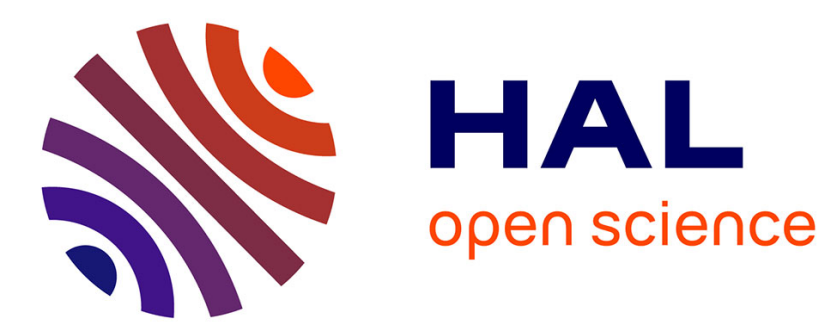

\title{
Excitonic and charge transfer interactions in tetracene stacked and T-shaped dimers
}

\author{
Daniel C. A. Valente, Mariana T Do Casal, Mario Barbatti, Thomas A \\ Niehaus, Adelia J A Aquino, Hans Lischka, Thiago M Cardozo
}

\section{- To cite this version:}

Daniel C. A. Valente, Mariana T Do Casal, Mario Barbatti, Thomas A Niehaus, Adelia J A Aquino, et al.. Excitonic and charge transfer interactions in tetracene stacked and T-shaped dimers. Journal of Chemical Physics, 2021, 154 (4), pp.044306. 10.1063/5.0033272 . hal-03126397

\section{HAL Id: hal-03126397 \\ https://hal.science/hal-03126397}

Submitted on 31 Jan 2021

HAL is a multi-disciplinary open access archive for the deposit and dissemination of scientific research documents, whether they are published or not. The documents may come from teaching and research institutions in France or abroad, or from public or private research centers.
L'archive ouverte pluridisciplinaire HAL, est destinée au dépôt et à la diffusion de documents scientifiques de niveau recherche, publiés ou non, émanant des établissements d'enseignement et de recherche français ou étrangers, des laboratoires publics ou privés. 


\section{Excitonic and Charge Transfer Interactions in Tetracene Stacked and T-shaped Dimers ${ }^{1}$}

Daniel C. A. Valente ${ }^{1}$, Mariana T. do Casal ${ }^{2}$, Mario Barbatti ${ }^{2}$, Thomas A. Niehaus ${ }^{3}$, Adelia J. A. Aquino $^{4,5}$, Hans Lischka ${ }^{5,6, a)}$, Thiago M. Cardozo ${ }^{1, a)}$

${ }^{1}$ Instituto de Química, Universidade Federal do Rio de Janeiro, Rio de Janeiro, Rio de Janeiro, Brazil. ${ }^{2}$ Aix Marseille University, CNRS, ICR, Marseille, France.

${ }^{3}$ Univ Lyon, Université Claude Bernard Lyon 1, CNRS, Institut Lumière Matière, F-69622, Villeurbanne, France.

${ }^{4}$ Department of Mechanical Engineering, Texas Tech University, Lubbock, Texas, USA.

${ }^{5}$ School of Pharmaceutical Sciences and Technology, Tianjin University, Tianjin, People’s Republic of China.

${ }^{6}$ Department of Chemistry and Biochemistry, Texas Tech University, Lubbock, Texas, USA.

a)Authors to whom correspondence should be addressed: thiago@iq.ufrj.br; Hans.Lischka@ttu.edu

\section{ABSTRACT}

Extended quantum chemical calculations were performed for the tetracene dimer to provide benchmark results, analyze the excimer survival process, and explore the possibility of using long-range-corrected (LC) time-dependent (TD) second-order density functional tight-biding (DFTB2) for this system. Ground- and first-excited-states optimized geometries, vertical excitations at relevant minima, and intermonomer displacement potential energy curves (PECs) were calculated for these purposes. Groundstate geometries were optimized with the scaled-opposite-spin (SOS) second-order Møller-Plesset perturbation theory (MP2) and LC-DFT (density functional theory) and LC-DFTB2 levels. Excited-state geometries were optimized with SOS-ADC(2) (algebraic diagrammatic construction to second-order) and the time-dependent approaches for the latter two methods. Vertical excitations and PECs were

\footnotetext{
${ }^{1}$ This article may be downloaded for personal use only. Any other use requires prior permission of the author and AIP Publishing. This article appeared in D. C. A. Valente et al. J. Chem. Phys. DOI:10.1063/5.0033272 (2021) and may be found at http://dx.doi.org/10.1063/5.0033272.
} 
compared to multireference configuration interaction DFT (DFT/MRCI). All methods predict the lowestenergy $S_{0}$ conformer to have monomers parallel and rotated relative to each other and the lowest $S_{1}$ conformer to be of a displaced-stacked type. LC-DFTB2, however, presents some relevant differences regarding other conformers for $\mathrm{S}_{0}$. Despite some state-order inversions, an overall good agreement between methods was observed in the spectral shape, state character, and PECs. Nevertheless, DFT/MRCI predicts that the $S_{1}$ state should acquire a doubly excited-state character relevant to the excimer survival process and, therefore, cannot be completely described by the single reference methods used in this work. PECs also revealed an interesting relation between dissociation energies and the intermonomer charge-transfer interactions for some states.

\section{INTRODUCTION}

Several potential advantages, such as low synthesis cost, have stimulated the search for organic optoelectronic materials. ${ }^{1}$ Among these materials, a particularly important class is that of the polycyclic aromatic hydrocarbons (PAHs) due to their potential application as organic semiconductors ${ }^{2}$ and their relevance for spintronics, ${ }^{3}$ astrochemistry, ${ }^{4}$ and nonlinear optics. ${ }^{5}$ Tetracene and pentacene, in particular, are the focus of a renewed interest due to the singlet fission phenomenon ${ }^{6}$ and the promise of increased efficiency in optoelectronic devices, with several reported theoretical ${ }^{7-10}$ and experimental ${ }^{11,12}$ studies $^{-1}$ focused on monomers and dimers of these molecules and their derivatives.

Multiple theoretical studies focused on tetracene monomers have been reported with various goals, including analyzing the biradical character of polyacenes ${ }^{13,14}$ or their excited-state nonadiabatic dynamics. ${ }^{15}$ The latter, for example, provided relevant information about the nonradiative relaxation mechanism after photoexcitation. Nevertheless, for singlet fission and other applications, the supramolecular properties of dimers and larger aggregates are also essential. Therefore, several studies 
have tackled these systems in small aggregates and crystals, ${ }^{7,16-22}$ in which excimer formation plays a central role. The latter process has been the subject of theoretical studies, such as for covalently linked tetracene dimers in the context of singlet fission, ${ }^{23}$ but further investigation, especially delivering benchmark results, would prove beneficial for the unmodified tetracene dimer. Such benchmarks could be used to analyze the reliability of methods employed to simulate the excimer formation and survival and determine the most relevant intermonomer interactions.

For the generation of benchmark results, comparison with available experimental data is essential. Both geometric and spectroscopic properties of the tetracene dimer have been experimentally reported. Katul and Zahlan first showed that tetracene in solution could form dimers in the ground state, redshifting the lowest absorption band maximum from 2.6 to $2.3 \mathrm{eV} \cdot{ }^{24} \mathrm{~A}$ similar result has been reported by Iannone and $\mathrm{Scott}^{25}$ (close to 2.6), who generated tetracene dimer by decomposing ditetracene in a solid host matrix. Fluorescence properties of tetracene change radically depending on its concentration in solution, going from a sharp peak localized at $2.6 \mathrm{eV}$ at low concentrations to a structureless band that peaks around $2.2 \mathrm{eV} .{ }^{24}$ Schouder et al. ${ }^{26}$ have recently explored the ground-state structure of tetracene dimers using experimental and theoretical techniques. They concluded that two geometries are consistent with the angular dispersion data generated by Coulomb explosion experiments of tetracene dimers inside helium droplets. These two geometries corresponded to parallel monomers, but differing in the angle between their long axes (either 0 or $25^{\circ}$ ).

Besides experimental results, comparison with previous theoretical work is also essential, as numerous calculations on the tetracene dimer and similar systems (like pentacene dimer) or derivatives have been reported. A theoretical work on PAH sheets using explicitly correlated approaches predicted a tetracene dissociation energy $\left(\mathrm{D}_{\mathrm{e}}\right)$ of $-9.4 \mathrm{kcal} / \mathrm{mol} .{ }^{27} \mathrm{Zimmerman}$ et al. ${ }^{7}$ analyzed the excited state of tetracene and pentacene clusters, predicting a doubly excited state near the singly-excited $\mathrm{S}_{1}$ state. Further work for tetracene and other molecules also predicted such a state to be present and relevant for singlet 
fission. ${ }^{8,10,23,28,29}$ Dynamics calculations have also been reported for tetracene dimers and higher oligomers, ${ }^{20,30}$ providing relevant information on exciton (de)localization, as an example. Based on these and several other theoretical and experimental results, mechanisms for singlet fission have been proposed, as well as heuristic guidelines on how to properly search through theoretical calculations for new candidates exhibiting this process. ${ }^{31}$

In addition to the doubly excited state, other types of states have also been proposed as relevant for the singlet fission process, and a recent study by Suarez et al. ${ }^{9}$ used descriptors ${ }^{32-34}$ based on the firstorder transition density matrix (1TDM) to study the importance of charge-transfer and charge-resonance states in this process for dimer conformations relevant for solid-state tetracene. This same technique can be applied to analyze the relevant interactions in the excimer survival process, ${ }^{35-37}$ and, recently, Cardozo et al. ${ }^{38}$ demonstrated through nonadiabatic excited-state dynamics the prominent role of intermolecular charge transfer in the excimer formation process for a benzene dimer.

Although several quantum chemical methods can be applied to calculating excited states for tetracene, the computational cost can quickly become prohibitive for aggregates. To reduce the costs, parameterized methods such as the second-order density functional-based tight-binding method (DFTB2 ${ }^{39}$ ), in combination with its time-dependent (TD) formulation, may provide an alternative, particularly since the implementation of long-range corrections (LC-TD-DFTB2 ${ }^{40,41}$ ). This approach has not yet been applied to model a tetracene dimer to the best of our knowledge. It has been successfully used to simulate the pyrene dimer photodynamics, ${ }^{42}$ but it certainly needs more validation, which must be performed compared to calculations using higher-level methods.

The main objective of the present work is to benchmark theoretical results for the tetracene dimer. Different types of methods were included to explore this system: DFT/MRCI, SOS-ADC(2)/SOS-MP2,

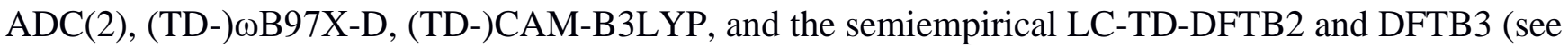
acronym definitions in the Computational Methods). Optimized geometries, vertical excitations, and 
potential energy curves were calculated and compared. Available experimental results for dimer geometries and absorption and emission spectra were also included in this comparison. Lastly, results were also analyzed using electronic descriptors based on the 1TDM to characterize the states and determine the relevant interactions during the excimer survival.

\section{COMPUTATIONAL METHODS}

Ground-state geometry optimizations $\left(\mathrm{S}_{0}\right)$ for a tetracene dimer were performed with the scaledopposite-spin version of the second-order Møller-Plesset (SOS-MP2 ${ }^{43}$ ), with density functional theory (DFT) using the range- and dispersion-corrected functional $\omega \mathrm{B} 97 \mathrm{X}-\mathrm{D},{ }^{44}$ and with the long-range corrected second-order density functional-based tight-binding (LC-DFTB2). For each of these methods, optimization of the first excited state $\left(S_{1}\right)$ and vertical excitations were computed with the corresponding excited-state approach: scaled-opposite-spin second-order algebraic diagrammatic construction (SOS$\mathrm{ADC}(2)^{45}$ ) for SOS-MP2, linear-response time-dependent DFT (TD- $\omega$ B97X-D) for DFT, and LC-TDDFTB2 $^{41}$ for LC-DFTB2. Third-order DFTB $\left(\right.$ DFTB3 $\left.^{46}\right)$, TD-CAM-B3LYP, ${ }^{47}$ and ADC $(2)^{48,49}$ were also applied. Combined density functional theory and multireference configuration interaction (DFT/MRCI ${ }^{50,51}$ ) calculations were used as the reference for vertical excitations due to previous

encouraging results. ${ }^{21,52,53}$ Vibrational frequencies were calculated with SOS-MP2/SOS-ADC(2), (TD-) $\omega$ B97X-D and, only for the ground state, with CAM-B3LYP. Symmetry was not imposed for dimer geometry optimizations but was used for vertical excitations since the predicted minima were symmetrical.

Approximated interaction energies were calculated as the difference between the dimer energy and the sum of the isolated monomers' electronic energies. $\mathrm{S}_{1}$ excimer stabilization energies (ESE) were calculated as the difference between $S_{1}$ vertical excitation and $S_{1}$ adiabatic excitation energies. As usual, the former was calculated as the lowest excitation energy at the $\mathrm{S}_{0}$-optimized geometry and the latter as 
the electronic energy difference between $S_{0}$ and $S_{1}$ at their optimized geometries. Dissociation energies for each state $\left(D_{e}\right)$ were estimated from potential energy curves as the difference in energy between the minimum energy structure and the structure with maximum intermonomer separation.

Charge transfer in a system can be quantified by the charge transfer value, ${ }^{32,54} \mathrm{CT}$, defined in Equation 1:

$$
\begin{aligned}
& \mathrm{CT}=\frac{1}{\Omega^{I}} \sum_{A, B \neq A} \Omega_{A B}^{I} \\
& \Omega_{A B}^{I}=\frac{1}{2} \sum_{\mu \in A} \sum_{\nu \in B}\left[\left(D^{0 I} S\right)_{\mu \nu}\left(S D^{0 I}\right)_{\mu \nu}+D_{\mu \nu}^{0 I}\left(S D^{0 I} S\right)_{\mu \nu}\right] \\
& \Omega^{I}=\sum_{A, B} \Omega_{A B}^{I}
\end{aligned}
$$

In Equations 1 to $3, \mathrm{~A}$ and $\mathrm{B}$ are fragments of the system, $\mathbf{D}^{\mathrm{OI}}$ is the one-particle transition density matrix (1TDM) between the ground (0) and excited state (I), and $\mathbf{S}$ is the orbital overlap matrix. For each excited state, an omega matrix $\left(\mathbf{\Omega}^{\mathrm{I}}\right)$ can be defined by varying the indexes $\mathrm{A}$ and $\mathrm{B}$ through all the fragments of the system.

CT values, omega matrices, dominant orbital transitions, oscillator strengths, and symmetries were used to compare excited states between methods. However, the first two properties were not included for doubly excited states as these are not well represented by 1TDM only.

SOS-MP2, ADC(2), and SOS-ADC(2) were carried out with Turbomole ${ }^{55,56}$ (versions 7.2 (mainly), 7.3, and 7.4) using the frozen core and the resolution of identity (RI) ${ }^{57-59}$ approximations, and appropriate

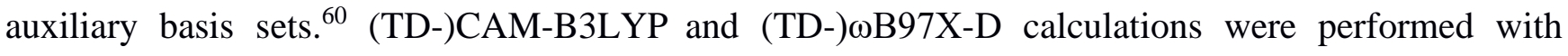
ORCA $^{61,62}$ (version 4.2.1) and Gaussian $09,{ }^{63}$ respectively. RI with appropriate auxiliary basis sets, ${ }^{64,65}$ increased grid (grid4 finalgrid5), and D3(BJ) dispersion corrections ${ }^{66,67}$ were used with CAM-B3LYP functional.

In the DFT/MRCI calculations, as developed by Grimme and Waletzke ${ }^{50}$ and redesigned by Marian et al., ${ }^{51,68-70}$ the R2018 hamiltonian ${ }^{69}$ and a 0.8 Hartree energy cutoff ("short") were used, based on DFT BH-LYP results. ${ }^{71}$ BH-LYP D3(BJ) dispersion corrections ${ }^{66}$ addition were necessary to obtain a bound 
ground state. ${ }^{29,51}$ The execution driver written by Crespo-Otero and Barbatti ${ }^{72}$ was used to run calculations. Only two excitations were allowed in the construction of the reference active space used in DFT/MRCI, and the number of orbitals and electrons were chosen analyzing the impact of increasing it in size on excited-state energies. An $(8,8)$ reference active space was found to be sufficient for DFT/MRCI (see Tables SI-SII in the Supplementary Material). Both basis sets def2-SVP and def2$\mathrm{SV}(\mathrm{P})^{73}$ were used in $\mathrm{S}_{0}$ and $\mathrm{S}_{1}$ optimizations. Results with the latter basis were used to explore excited states in vertical excitations.

LC-TD-DFTB2 calculations were carried out using a development version of the DFTB+ program package. ${ }^{74}$ The ob2-1-1-base ${ }^{75}$ Slater Koster (SK) set was used for LC-TD-DFTB2 calculations and the 3ob-3-1 ${ }^{76}$ SK set for DFTB3 ones, along with a dispersion correction of Lennard-Jones form ${ }^{77}$ with $^{2}$ universal force field (UFF) parameters. ${ }^{78}$ TheoDORE $^{32-34}$ was used to calculate CT value and omega matrix for each state. Images of the molecules were created with Jmol. ${ }^{79}$

Due to previous results concluding that basis set superposition error (BSSE) corrections should not be used with small basis sets for stacked dimers, ${ }^{80}$ these corrections were not applied in the present study.

\section{RESULTS AND DISCUSSION}

\section{A. So and $S_{1}$ optimized dimer geometries}

Dimer structures were optimized using the def2-SVP basis set and the methods displayed in TABLE I. Results were classified according to the structures obtained, as shown in FIG. 1. for the ground state. A T-shaped-type geometry was also included due to its particular importance in the tetracene crystal phase. Other geometries are identified by the acronyms Rot, PD, and DS, which stand for, respectively, rotated, parallel displaced (consistent with previous studies ${ }^{26}$ ), and displaced stacked. The state used to optimize the respective geometry is identified following the acronym (e.g., Rot1-S 0 or PD1-S 1 . 


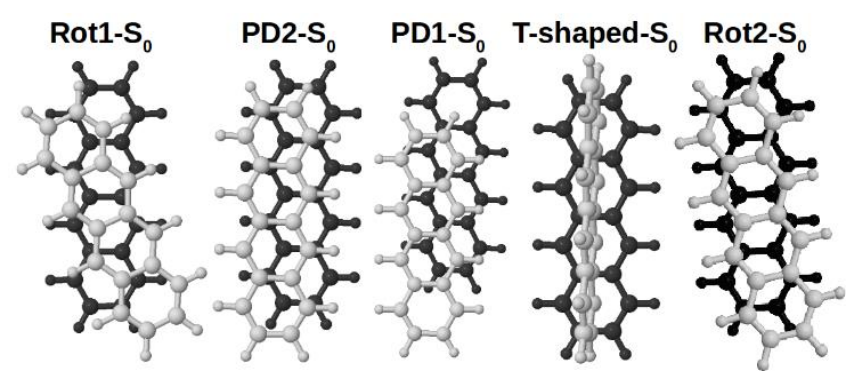

FIG. 1. Relevant optimized geometries obtained for a tetracene dimer in the ground state with SOS-MP2 and def2-SVP basis set. Relative energy increases from left to right (тAвLE I). LC-DFTB2 Rot2-So geometry was also included.

TABLE I. Relative energies $(\mathrm{kcal} / \mathrm{mol})$ of $\mathrm{S}_{0}$ minimum geometries for the tetracene dimer, with def2SVP basis. If the conformation type changed during optimization, the final geometry is indicated.

\begin{tabular}{|c|c|c|c|c|c|}
\hline \multirow{2}{*}{$\begin{array}{l}\text { Optimized } \\
\text { geometries }\end{array}$} & \multicolumn{5}{|c|}{ Relative energy of $S_{0}$ optimized geometries $(\mathrm{kcal} / \mathrm{mol})$} \\
\hline & $\omega B 97 X-D$ & SOS-MP2 & CAM-B3LYP & LC-DFTB2* & DFTB3* \\
\hline Rot1-S $\mathrm{S}_{0}$ & 0.00 & 0.00 & 0.00 & 0.00 & 0.00 \\
\hline Rot2-S $\mathrm{S}_{0}$ & Rot1- $\mathrm{S}_{0}$ & Rot1-S $\mathrm{S}_{0}$ & Rot1-S $S_{0}$ & -0.02 & 0.05 \\
\hline $\mathrm{T}$-shaped-S $\mathrm{S}_{0}$ & $\mathrm{PD} 2-\mathrm{S}_{0}$ & 6.25 & DS1-S type $^{* *}$ & Rot2-S 0 & Rot2-S $\mathrm{S}_{0}$ \\
\hline $\mathrm{PD} 2-\mathrm{S}_{0}$ & 0.82 & 1.04 & 0.93 & 0.03 & 0.11 \\
\hline $\mathrm{PD} 1-\mathrm{S}_{0}$ & $\mathrm{PD} 2-\mathrm{S}_{0}$ & 3.03 & 2.62 & $\mathrm{PD} 2-\mathrm{S}_{0}$ & $\mathrm{PD} 2-\mathrm{S}_{0}$ \\
\hline
\end{tabular}

TABLE II. Geometrical parameters for $\mathrm{S}_{0}$ and $\mathrm{S}_{1}$ optimized geometries of the tetracene dimer. $\mathrm{D}$ is the distance between the centers-of-mass of each monomer. The angles $\alpha$ and $\beta$ and the dihedral angle $\gamma$ are defined in FIG. 2.

\begin{tabular}{|c|c|c|c|c|c|c|c|c|c|c|c|c|c|c|c|c|}
\hline \multirow{3}{*}{$\begin{array}{l}\text { Optimized } \\
\text { Geometry }\end{array}$} & \multicolumn{16}{|c|}{ Geometrical parameters } \\
\hline & \multicolumn{4}{|c|}{ 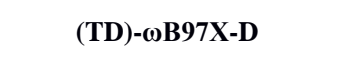 } & \multicolumn{4}{|c|}{ SOS-MP2/SOS-ADC(2) } & \multicolumn{4}{|c|}{ (TD)-CAM-B3LYP } & \multicolumn{4}{|c|}{ LC-(TD-)DFTB2 } \\
\hline & $\begin{array}{l}\alpha \\
\left({ }^{\circ}\right)\end{array}$ & $\begin{array}{c}\boldsymbol{\beta} \\
\left({ }^{\circ}\right)\end{array}$ & $\begin{array}{l}\text { D } \\
(\AA)\end{array}$ & $\begin{array}{l}\gamma \\
\left({ }^{\circ}\right)\end{array}$ & $\begin{array}{c}\alpha \\
\left({ }^{\circ}\right)\end{array}$ & $\begin{array}{c}\boldsymbol{\beta} \\
\left({ }^{\circ}\right)\end{array}$ & $\begin{array}{l}\text { D } \\
(\AA)\end{array}$ & $\begin{array}{c}\gamma \\
\left({ }^{\circ}\right)\end{array}$ & $\begin{array}{c}\alpha \\
\left({ }^{\circ}\right)\end{array}$ & $\begin{array}{c}\boldsymbol{\beta} \\
\left({ }^{\circ}\right)\end{array}$ & $\begin{array}{l}\text { D } \\
(\AA)\end{array}$ & $\begin{array}{c}\gamma \\
\left({ }^{\circ}\right)\end{array}$ & $\begin{array}{c}\alpha \\
\left({ }^{\circ}\right)\end{array}$ & $\begin{array}{l}\boldsymbol{\beta} \\
\left(^{\circ}\right)\end{array}$ & $\begin{array}{l}\text { D } \\
(\AA)\end{array}$ & $\begin{array}{l}\gamma \\
\left({ }^{\circ}\right)\end{array}$ \\
\hline
\end{tabular}




\begin{tabular}{|c|c|c|c|c|c|c|c|c|c|c|c|c|c|c|c|c|}
\hline Rot1-S $S_{0}$ & 179.1 & 96.1 & 3.48 & 21.9 & 179.7 & 94.8 & 3.44 & 21.9 & 179.3 & 93.8 & 3.52 & 22.7 & 178.7 & 91.8 & 3.49 & 18.6 \\
\hline $\operatorname{Rot} 2-S_{0}$ & & - & & & & - & & & & - & & & 179.0 & 90.0 & 3.60 & 10.7 \\
\hline $\begin{array}{c}\text { T-shaped- } \\
\mathrm{S}_{0}\end{array}$ & & - & & & 178.9 & 176.0 & 4.99 & -1.3 & & - & & & & & & \\
\hline PD2-S $S_{0}$ & 179.7 & 107.4 & 3.73 & 0.1 & 178.7 & 106.1 & 3.68 & 0.1 & 179.7 & 108.2 & 3.79 & 0.1 & 179.8 & 82.3 & 3.62 & 0.0 \\
\hline PD1-S ${ }_{0}$ & & - & & & 178.2 & 104.5 & 4.67 & 1.5 & 177.3 & 107.4 & 4.58 & -0.1 & & & & \\
\hline DS1-S 1 & 177.0 & 101.5 & 3.33 & 0.0 & 175.8 & 103.9 & 3.26 & 0.0 & 176.0 & 103.4 & 3.33 & -0.1 & 174.0 & 89.7 & 3.19 & 0.0 \\
\hline $\mathrm{PD} 1-\mathrm{S}_{1}$ & 179.0 & 97.7 & 4.00 & -0.1 & 177.4 & 100.6 & 3.91 & 0.6 & 178.6 & 97.6 & 4.04 & -0.1 & 173.5 & 89.9 & 4.05 & 0.3 \\
\hline
\end{tabular}

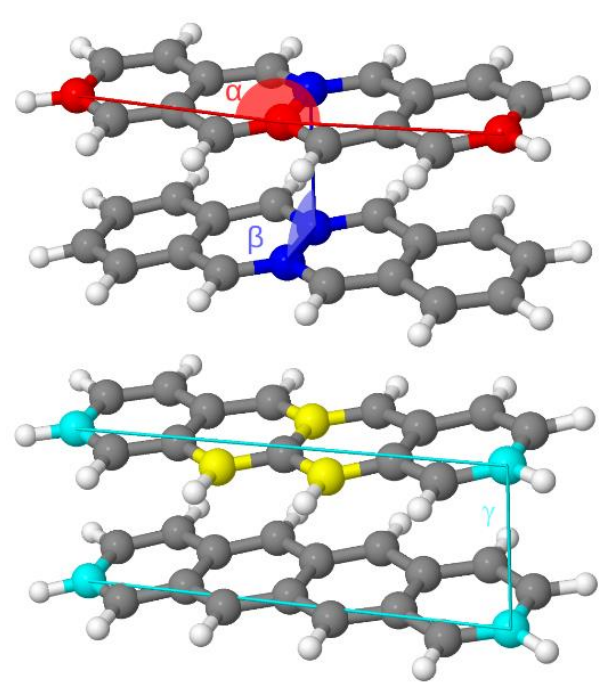

FIG. 2. Atoms used to define relevant geometrical parameters: angles $\alpha$ (red) and $\beta$ (blue) and dihedral angle $\gamma$ (cyan). The yellow atoms were used to construct the PECs discussed in Section III. C.

All methods, except LC-DFTB2, consistently predict the lowest $\mathrm{S}_{0}$ minimum to be the rotated type conformer denoted Rot1-S (TABLE I and FIG. 1), in which both monomers are parallel, and a nonzero angle is held between their long axes (TABLE II). This finding is also consistent with theoretical and experimental results reported by Schouder et al. ${ }^{26}$ LC-DFTB2 predicts two nearly degenerate rotated type minima, Rot $1-\mathrm{S}_{0}$, with intermonomer dihedral close to $19^{\circ}$ and consistent with the other methods, 
and Rot2-S $\mathrm{S}_{0}$ with a smaller dihedral (close to $11^{\circ}$ ), the latter with energy lower by only $0.02 \mathrm{eV}$. This Rot2-S $\mathrm{S}_{0}$ geometry converges at SOS-MP2, CAM-B3LYP, and $\omega$ B97X-D to the Rot1-S minimum (TABLE I). At SOS-MP2 level, other $\mathrm{S}_{0}$ minima are predicted to have higher energies, which rises with the decreasing alignment of aromatic rings: PD2-S 0 , PD1- $\mathrm{S}_{0}$, and T-shaped- $\mathrm{S}_{0}$. This order is also reflected in the interaction energies (TABLE III). CAM-B3LYP and $\omega$ B97X-D predict similar conformers and relative energies in several cases, including the lowest $\mathrm{S}_{0}$ minimum, although some conformations, such as the $\mathrm{T}$-shaped- $\mathrm{S}_{0}$, were predicted not to have minima.

Comparison with SOS-MP2 PD1-S 0 and T-shaped-S $\mathrm{S}_{0}$ geometries suggests that both LC-DFTB2 and DFTB3 lack appreciable minima in these conformations. These two methods also predict nearly degenerate PD2-S 0 , Rot1-S 0 , and Rot2-S optimized geometries, disagreeing with numerical values predicted by other methods.

The predicted lowest energy $S_{0}$ minimum geometry for the tetracene dimer, rotated type, is consistent with previous results based on experiments and DFT optimizations, ${ }^{26}$ and on force-field calculations. ${ }^{81}$ The stability order of other $\mathrm{S}_{0}$ minima in TABLE I (PD2-S, PD1-S 0 , and T-shaped-S $\left.\mathrm{S}_{0}\right)$ is also consistent with previous studies of naphthalene, anthracene, and tetracene dimers. ${ }^{82-84}$ SOS-MP2

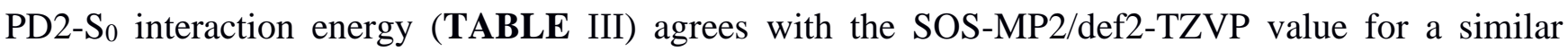
configuration reported by Silva et al. ${ }^{27}$ Spillebout et al. ${ }^{16}$ argued that a $\mathrm{C}_{2}$ geometry (rotated similar to Rot1- $\mathrm{S}_{0}$ ) is unstable for tetracene and pentacene dimers based on $\omega$ B97X-D/6-311G vibrational frequencies, whereas a PD2-S $\mathrm{S}_{0}$ type geometry is a minimum. However, these results for the Rot $1-\mathrm{S}_{0}$ are not in agreement with the ones presented in this study or those reported by Schouder et al. ${ }^{26}$

TABLE III. Interaction energies for $\mathrm{S}_{0}$ optimized geometries of the tetracene dimer $(\mathrm{kcal} / \mathrm{mol})$.

\begin{tabular}{lllll}
\hline \multirow{3}{*}{ Method } & \multicolumn{4}{c}{ Interaction energy $(\mathrm{kcal} / \mathrm{mol})$} \\
\cline { 2 - 5 } & Rot1-S & PD2-S & PD1-S $_{0}{ }^{\#}$ & T-shaped-S ${ }^{\#}$ \\
\hline
\end{tabular}




\begin{tabular}{ccccc}
\hline SOS-MP2 & -16.93 & -15.89 & -13.90 & -10.68 \\
WB97X-D & -20.42 & -19.60 & - & - \\
CAM-B3LYP & -17.62 & -16.69 & -15.00 & - \\
LC-DFTB2 & -18.87 & -18.75 & -14.67 & -10.10 \\
\hline
\end{tabular}

\# SOS-MP2 geometries were used for LC-DFTB2, as no minima were predicted with the latter (see TABLE I)

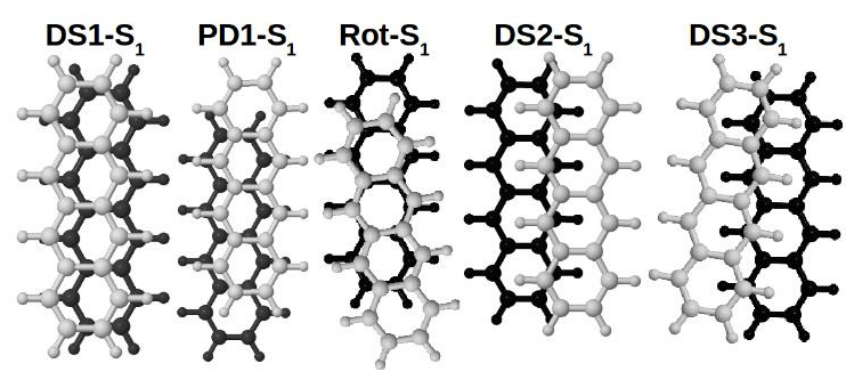

FIG. 3. Relevant optimized geometries obtained for a tetracene dimer in the first excited state with SOSADC(2) and def2-SVP basis set. Relative energies increase from left to right (TABLE IV). The TDCAM-B3LYP DS2-S 1 and TD- $\omega$ B97X-D DS3-S 1 geometries were also included.

TABLE IV. Relative energies $(\mathrm{kcal} / \mathrm{mol})$ for the $S_{1}$ optimized geometries of the tetracene dimer, with def2-SVP basis set unless stated otherwise. If the conformation type changed during optimization, the final geometry is indicated.

\begin{tabular}{|c|c|c|c|c|}
\hline \multirow{2}{*}{$\begin{array}{l}\text { Optimized } \\
\text { geometries }\end{array}$} & \multicolumn{4}{|c|}{ Relative energy of $S_{1}$ optimized geometries $(\mathrm{kcal} / \mathrm{mol})$} \\
\hline & $\omega B 97 X-D$ & SOS-ADC(2) & CAM-B3LYP & LC-TD-DFTB2 \\
\hline DS1- $S_{1}$ & 0.00 & 0.00 & 0.00 & 0.00 \\
\hline PD1-S & 3.19 & 3.15 & 2.52 & 3.00 \\
\hline Rot $1-\mathrm{S}_{0} *$ & PD1-S ${ }_{1}$ & 4.35 Rot- $\mathrm{S}_{1}$ & PD1-S & DS1-S \\
\hline T-shaped- $\mathrm{S}_{0} *$ & $9.78 \mathrm{DS} 3-\mathrm{S}_{1} * *$ & 17.89 & 9.56 DS2-S & DS1-S \\
\hline
\end{tabular}


** Intermonomer dihedral $\gamma$ close to $7^{\circ}$.

Concerning the excited state, all methods predicted a consistent lowest energy minimum (DS1-S 1 , see TABLE IV and FIG. 3), similar to a $\mathrm{D}_{2 \mathrm{~h}}$ stacked model, but with one monomer displaced along its shorter axis (see TABLE II). Regarding other conformations, PD1-S 1 was consistently predicted as a higher energy minimum by all methods. Rot $1-\mathrm{S}_{0}$ and $\mathrm{T}$-shaped-S $\mathrm{S}_{0}$ conformers were also optimized for $\mathrm{S}_{1}$, and in all cases, the conformation either changed to PD1-S 1 , DS1-S 1 , or conformers with higher relative energy (greater than $4 \mathrm{kcal} / \mathrm{mol}$, TABLE IV). Hence, among the calculated geometries, only the DS1-S $S_{1}$ should be a relevant minimum geometry in the $S_{1}$ state. Particularly at SOS-ADC(2) level, the Rot1-S $\mathrm{S}_{0}$ initial conformation converged to a different rotated conformer (Rot-S 1$)$, with an intermonomer dihedral angle close to $10^{\circ}$ instead of $20-22^{\circ}$.

The DS1-S 1 geometry should be sufficiently close to an eclipsed geometry to allow the latter to be reached, should it be more stable. However, given the relevance of eclipsed $\mathrm{D}_{2 \mathrm{~h}}$ structure for aromatic excimers, ${ }^{38,42}$ besides parallel displaced ones, ${ }^{21}$ two additional geometries were considered. An eclipsed $\mathrm{D}_{2 \mathrm{~h}}$ geometry and a parallel displaced one with one monomer slipped by $0.05 \AA$ in the long and short axis (denoted DS4-S 1 ). After optimization, SOS-ADC(2)/def2-SV(P) predicts the $\mathrm{D}_{2 \mathrm{~h}}$ energy to be higher by $2.2 \mathrm{kcal} / \mathrm{mol}$ relative to $\mathrm{DS} 1-\mathrm{S}_{1}$, and the $\mathrm{DS} 4-\mathrm{S}_{1}$ structure $\left(\mathrm{C}_{1}\right.$ symmetry) to converge to the $\mathrm{DS} 1-\mathrm{S}_{1}$ geometry. Concerning TDDFT calculations using the levels $\omega$ B97X-D/def2-SV(P) and CAMB3LYP/def2-SVP, the eclipsed $\mathrm{D}_{2 \mathrm{~h}}$ structure was higher in energy by $0.37 \mathrm{kcal} / \mathrm{mol}$ and $0.20 \mathrm{kcal} / \mathrm{mol}$, respectively, than the DS1-S 1 structure, suggesting a flatter potential energy surface relative to SOSADC(2). The DS4-S 1 structure converged to a geometry similar to the optimized D2h for CAM-B3LYP, and to the DS1-S minimum for $\omega$ B97X-D. In all tested cases, the DS1-S 1 was still the lowest $\mathrm{S}_{1}$ energy geometry obtained. 


\section{B. Dimer Vertical Excitations at Optimized Geometries}

Vertical excitations for the dimer were calculated with the def2-SV(P) at the $\mathrm{S}_{0}$ and $\mathrm{S}_{1}$ minima optimized with the same basis set. The latter geometries were very similar to def2-SVP optimized ones (TABLE I and TABLE IV, FIG. 1 and FIG. 3). Results for the monomer at SOS-MP2/def2-SV(P) $\mathrm{S}_{0}$ optimized geometry were also included for comparison. Excitation energies, symmetries, and oscillator strengths are also shown in Tables SIII-SVII.

TABLE V. Excitation energy (EE, eV) and oscillator strength $(f)$ for the ${ }^{1} \mathrm{~L}_{\mathrm{a}}$ and ${ }^{1} \mathrm{~L}_{\mathrm{b}}$ states of the tetracene monomer. SOS-MP2/def2-SV(P) optimized geometry was used for all calculations.

\begin{tabular}{|c|c|c|c|c|}
\hline \multirow{2}{*}{ Method } & \multicolumn{2}{|c|}{${ }^{1} \mathbf{L}_{\mathrm{a}}\left(\mathbf{1}^{1} \mathbf{B}_{2 u}\right)$} & \multicolumn{2}{|c|}{${ }^{1} \mathbf{L}_{\mathrm{b}}\left(\mathbf{1}^{1} \mathbf{B}_{3 \mathrm{u}}\right)$} \\
\hline & EE $(e V)$ & $f$ & EE $(e V)$ & $f$ \\
\hline DFT/MRCI & $\begin{array}{l}2.69 \\
2.74^{\mathrm{a}}\end{array}$ & $\begin{array}{c}0.127 \\
0.109^{\mathrm{a}}\end{array}$ & $\begin{array}{l}3.27 \\
3.22^{\mathrm{a}}\end{array}$ & $\begin{array}{c}0.004 \\
0.002^{\mathrm{a}}\end{array}$ \\
\hline SOS-ADC(2) & 3.33 & 0.111 & 3.50 & 0.001 \\
\hline $\mathrm{ADC}(2)$ & 3.07 & 0.101 & 3.59 & 0.001 \\
\hline TD-œB97X-D & 2.88 & 0.087 & 3.71 & 0.003 \\
\hline LC-TD-DFTB2 & 3.03 & 0.113 & 4.01 & 0.191 \\
\hline CASPT $^{2}{ }^{b}$ & 2.79 & 0.125 & 3.15 & 0.004 \\
\hline Experimental & $\begin{array}{l}2.71^{\mathrm{c}} \\
2.60^{\mathrm{d}}\end{array}$ & - & $\begin{array}{l}3.32^{\mathrm{c}} \\
3.14^{\mathrm{d}}\end{array}$ & - \\
\hline
\end{tabular}

Regarding the monomer (TABLE V), DFT/MRCI predicts excitation energies of 2.69 and $3.27 \mathrm{eV}$ for $1^{1} \mathrm{~B}_{2 u}$ and $1^{1} \mathrm{~B}_{3 \mathrm{u}}$ states, in excellent agreement with experimental results ${ }^{87,88}$ and previously reported calculations with DFT/MRCI, ${ }^{85}$ using both SV(P) and TZVP basis sets, and CASPT2.${ }^{86}$ Other methods predict higher excitation energies for both states and a varying energy gap between them, such as 0.17 $\mathrm{eV}$ [SOS-ADC(2)] and $0.98 \mathrm{eV}$ (LC-TD-DFTB2). In particular, SOS-ADC(2) has the highest overestimation of ${ }^{1} \mathrm{~L}_{a}$, but the closest prediction of ${ }^{1} \mathrm{~L}_{b}$ relative to experimental results, among the single- 
reference methods. Excepting LC-TD-DFTB2, all methods predict a bright $\mathrm{S}_{1}$ state and a $\mathrm{S}_{2}$ with small, but non-zero oscillator strength for the monomer (TABLE V), which agrees with the experiments. ${ }^{88}$
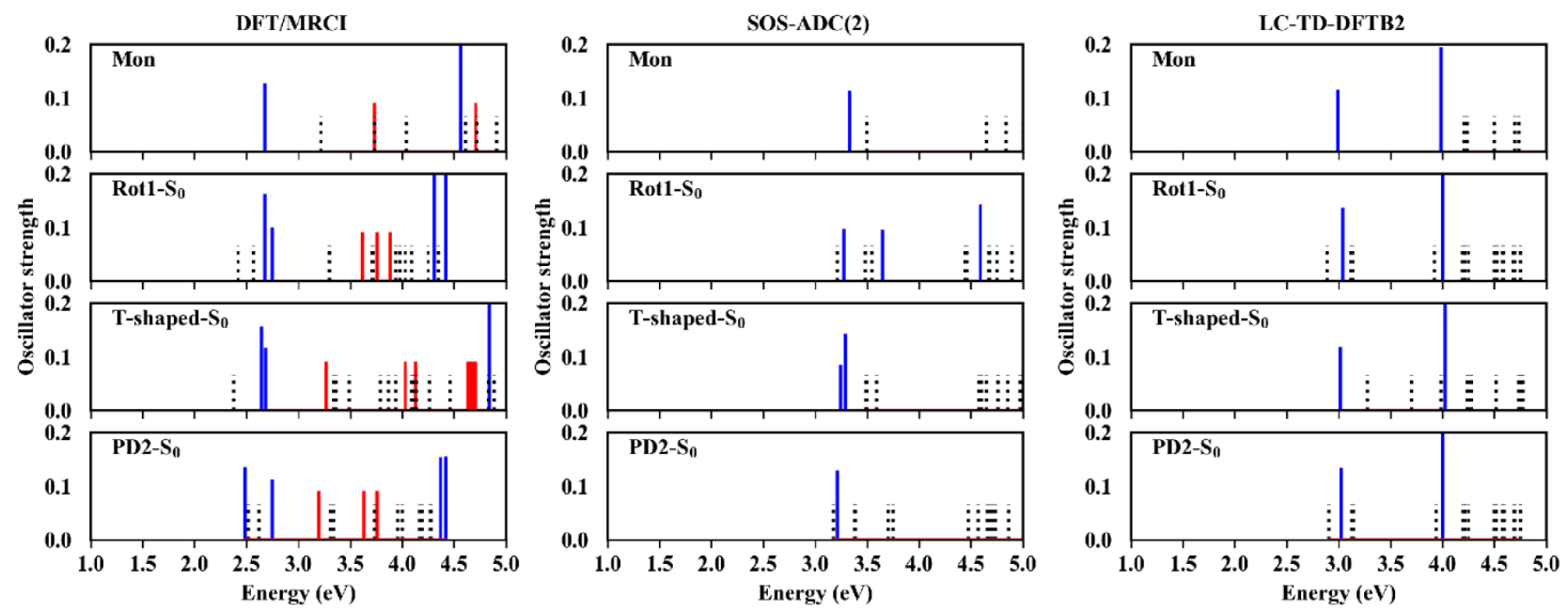

FIG. 4. Excitation energies and oscillator strengths for the tetracene monomer (Mon) and dimer $\mathrm{S}_{0}$ optimized geometries (FIG. 1). Bright singly excited $(f>0.05)$, dark singly excited, and doubly excited states are represented by solid blue, dotted black, and solid red lines, respectively. The height is proportional to the oscillator strengths for the bright states and fixed for the others. LC-DFTB2 Mon, Rot1-S 0 , and PD2-S geometries were used for LC-TD-DFTB2, and SOS-MP2 geometries in all other cases. Fig. S1 contains all methods used.

There is an overall good agreement among dimer spectra using different methods (FIG. 4 and FIG. 5). Focusing on $\mathrm{S}_{1}-\mathrm{S}_{4}$ states for all geometries, we see that other methods predict higher excitation energies relative to DFT/MRCI, particularly SOS-ADC(2). This general pattern could be partly due to the monomer itself, as it also appears for the $S_{1}$ and $S_{2}$ states of the latter (TABLE V). For the $S_{0}$ minimum dimer geometries investigated - Rot1- $\mathrm{S}_{0}, \mathrm{~T}$-shaped-S $\mathrm{S}_{0}, \mathrm{PD} 2-\mathrm{S}_{0}-$ all methods predict a bright 
state to be either $\mathrm{S}_{1}$ or within $0.3 \mathrm{eV}$ of it (FIG. 4). DFT/MRCI predicts a dark $\mathrm{S}_{1}$ state for all geometries except PD2-S $\mathrm{S}_{0}$, where the $\mathrm{S}_{2}$ dark state is nearly degenerate with the $\mathrm{S}_{1}$ bright state (FIG. 4). Other methods follow closely, except for the T-shaped-S $\mathrm{S}_{0}$ geometry, where a bright $\mathrm{S}_{1}$ state, similar in energy to the monomer bright $\mathrm{S}_{1}$ state, is predicted by SOS-ADC(2) and LC-TD-DFTB2 (FIG. 4). The excimer geometry, DS1-S 1 conformer, presents a rather distinct picture as all methods predict the stabilization of the first dark state, which is lower by at least $1.0 \mathrm{eV}$ compared to other singly excited states, including the first bright state (FIG. 5).

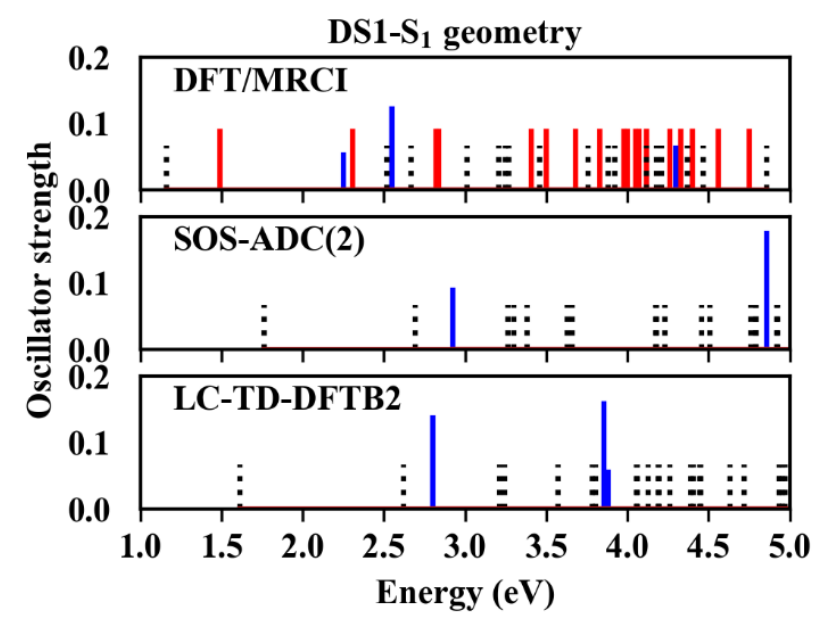

FIG. 5. Same as FIG. 4, but focusing on DS1-S 1 optimized geometry (FIG. 3) and varying the method. Bright singly excited $(f>0.05)$, dark singly excited, and doubly excited states are represented by solid blue, dotted black, and solid red lines, respectively. DFT/MRCI calculations used SOS-ADC(2) geometry. SOS-ADC(2) and LC-TD-DFTB2 used geometries optimized at the same level. Fig. S2 contains all methods used.

Current implementations of TDDFT and TD-DFTB cannot predict doubly excited states (due to the adiabatic approximation of the time-dependent correlation-exchange potential ${ }^{89}$ ); neither can ADC(2) (due to the expansion of the $2 \mathrm{p}-2 \mathrm{~h}$ matrix elements only to the zeroth order of perturbation theory ${ }^{48}$ ). 
Because at the Rot1-S 0 , PD2-S $\mathrm{S}_{0}$, and T-shaped-S $\mathrm{S}_{0}$ geometries, DFT/MRCI predicts doubly excited states much higher than $\mathrm{S}_{1}$ (by $1.0 \mathrm{eV}$ or more) and at least 0.5 higher than the first bright states (FIG. 4), TDDFT, TD-DFTB, and ADC(2) can be applied to describe the absorption spectrum without a problem. However, at the excimer geometry, DS1-S 1 , a low-lying doubly excited state is predicted to be only 0.4 $\mathrm{eV}$ above the $\mathrm{S}_{1}$ state and located lower than the first bright state (FIG. 5). Hence, this state is expected to become important for excimer formation and survival, limiting the applicability of these methods. Previous studies also reported the existence of a low-lying doubly excited state for the tetracene dimer ${ }^{7,8}$ and related systems such as pentacene $e^{7,90}$ and covalently linked tetracene dimers. ${ }^{23}$

Regarding comparison to experimental data for the tetracene dimer in solution, Katul and Zahlan ${ }^{24}$ reported the first absorption maximum close to $2.3 \mathrm{eV}$, and Iannone and $\mathrm{Scott}^{25}$ reported a similar value (close to $475 \mathrm{~nm}, 2.6 \mathrm{eV}$ ) for a tetracene dimer in a solid host matrix. These values are consistent with the first and second DFT/MRCI bright states $(f>0.05)$ for all three $\mathrm{S}_{0}$ optimized geometries (FIG. 4, TABLE VI): $\mathrm{S}_{3}(2.68 \mathrm{eV})$ and $\mathrm{S}_{4}(2.75 \mathrm{eV})$ at Rot $1-\mathrm{S}_{0}, \mathrm{~S}_{1}(2.49 \mathrm{eV})$ and $\mathrm{S}_{4}(2.75 \mathrm{eV})$ at PD2-S $\mathrm{S}_{0}$ and $\mathrm{S}_{2}$ $(2.64 \mathrm{eV})$ and $\mathrm{S}_{3}(2.69 \mathrm{eV})$ at $\mathrm{T}$-shaped-S $\mathrm{S}_{0}$. Since the latter geometry has relative energy much higher than the others, it is unlikely to contribute, but PD2-S $\mathrm{S}_{0}$ conformer is higher by near $1 \mathrm{kcal} / \mathrm{mol}$ at SOSMP2/def2-SV(P) level (TABLE I), and it could be populated if the temperature is high enough. Other methods predict a first aborption maximum at energies higher than DFT/MRCI by 0.16-0.72 eV (TABLE VI). The fluorescence spectrum of tetracene dimers trapped in a poly(methyl methacrylate) matrix shows a broad band, which has a peak maximum at $2.2 \mathrm{eV}$, another peak at $2.1 \mathrm{eV}$, and a weak shoulder at 1.9 $\mathrm{eV}$, as reported by Iannone and Scott. ${ }^{25}$. Comparison with these results shows that our vertical emission energies are lower, ranging between $1.16 \mathrm{eV}$ (DFT/MRCI) and $1.77 \mathrm{eV}(\mathrm{SOS}-\mathrm{ADC}(2)$ (TABLE VI). From shifts in the fluorescence excitation spectra between monomer and dimer of $250 \mathrm{~cm}^{-1}$ and the experimental Stokes shift of $300 \mathrm{~cm}^{-1}$, Iannone and Scott estimate the tetracene pair separation to lie between 4 to $8 \AA$ in the matrix. The weaker interaction in this case as compared to the one in the present 
dimer with a distance of $3.26 \AA$ might be one reason for the discrepancies between calculated and experimental emission energies, in addition to deficiencies of the computational methods.

TABLE VI. Excitation energy $(\mathrm{eV})$ for relevant states of the tetracene dimer for the processes considered. For the absorption, the first two bright states $(f>0.05)$ are included for both Rot1-S $\mathrm{S}_{0}$ and PD2- $S_{0}$ geometries. The adiabatic state is indicated in parenthesis. For the emission, the $\mathrm{S}_{1}$ state at DS1$\mathrm{S}_{1}$ geometry is included.

\begin{tabular}{|c|c|c|c|c|c|c|c|c|}
\hline \multirow[b]{2}{*}{ Process } & \multirow[b]{2}{*}{ Geometry } & \multirow[b]{2}{*}{$\begin{array}{c}\text { Relevant } \\
\text { state }\end{array}$} & \multicolumn{5}{|c|}{ Method } & \multirow[t]{2}{*}{ Experimental } \\
\hline & & & DFT/MRCI & $\begin{array}{c}\text { SOS- } \\
\text { ADC(2) }\end{array}$ & $\operatorname{ADC}(2)$ & $\begin{array}{c}\text { TD- } \\
\omega B 97 X-D\end{array}$ & $\begin{array}{l}\text { LC-TD- } \\
\text { DFTB2 }\end{array}$ & \\
\hline \multirow{4}{*}{ Absorption } & \multirow{2}{*}{ Rot1-S $\mathrm{S}_{0}$} & $\begin{array}{c}\text { First } \\
\text { bright }\end{array}$ & $2.68\left(\mathrm{~S}_{3}\right)$ & $3.28\left(\mathrm{~S}_{2}\right)$ & $2.93\left(\mathrm{~S}_{1}\right)$ & $2.97\left(\mathrm{~S}_{2}\right)$ & $3.04\left(\mathrm{~S}_{2}\right)$ & \multirow{4}{*}{$2.3^{\mathrm{a}}-2.6^{\mathrm{b}}$} \\
\hline & & $\begin{array}{l}\text { Second } \\
\text { bright }\end{array}$ & $2.75\left(\mathrm{~S}_{4}\right)$ & $3.65\left(\mathrm{~S}_{6}\right)$ & $3.13\left(\mathrm{~S}_{4}\right)$ & $3.27\left(\mathrm{~S}_{4}\right)$ & $4.00\left(\mathrm{~S}_{6}\right)$ & \\
\hline & \multirow{2}{*}{ PD2-S ${ }_{0}$} & $\begin{array}{l}\text { First } \\
\text { bright }\end{array}$ & $2.49\left(\mathrm{~S}_{1}\right)$ & $3.21\left(\mathrm{~S}_{2}\right)$ & $2.87\left(\mathrm{~S}_{1}\right)$ & $2.91\left(\mathrm{~S}_{2}\right)$ & $3.04\left(\mathrm{~S}_{2}\right)$ & \\
\hline & & $\begin{array}{l}\text { Second } \\
\text { bright }\end{array}$ & $2.75\left(\mathrm{~S}_{4}\right)$ & - & $3.14\left(\mathrm{~S}_{4}\right)$ & - & $4.00\left(\mathrm{~S}_{6}\right)$ & \\
\hline Emission & DS1-S ${ }_{1}$ & $S_{1}$ & 1.16 & 1.77 & 1.42 & 1.56 & 1.62 & $1.9-2.2^{\mathrm{b}}$ \\
\hline
\end{tabular}

Besides the general overview of the spectra, it is also important to compare the particular nature of states among methods. Oscillator strengths, symmetries, omega matrices, and CT values for low-lying states $\left(\mathrm{S}_{1}-\mathrm{S}_{4}\right)$ were employed to identify analogous states among methods. Omega matrices and CT values require defining proper fragments, and we used two schemes here (Fig. S3). To calculate CT values, we considered each monomer as a fragment, such that the CT descriptor quantifies intermonomer charge-transfer interactions. To calculate omega matrices, we used a more detailed grid. Each carbon was defined as a fragment, and, in the dimer case, the first half of the fragments belongs to a monomer, while the second half to the other. Hydrogen atoms were included in the fragment of the respective bonded carbon. Examples of omega matrices are shown in FIG. 6. Each cell specifies the weight of a given charge-transfer for the excitation considered, and the respective line and column specify the 
number, with origin at the lower left corner, of the two fragments involved (provided they are not equal). ${ }^{32}$

With this fragmentation scheme, each omega matrix for the dimer can be divided into four groups of fragments: upper left and lower right (“diagonal” blocks), and upper right and lower left ("off-diagonal” blocks). For two dominant off-diagonal blocks (such as in $\mathrm{S}_{2}$ state at Rot1-S $\mathrm{S}_{0}$ in FIG. 6), both the electron and the hole are on the same monomer (excitonic resonance states), whereas for two dominant diagonal blocks (as in $\mathrm{S}_{1}$ state at Rot1-S $\mathrm{S}_{0}$ in FIG. 6) they are separated on different monomers (charge-resonance (CR) states). ${ }^{32}$ If a single diagonal block is dominant (such as in $\mathrm{S}_{2}$ at T-shape- $\mathrm{S}_{0}$ geometry in FIG. 7), then the exciton is localized on a single monomer, and the state is locally excited. ${ }^{32}$ A single dominant off-diagonal block corresponds to a charge-transfer (CT) state (exemplified by $\mathrm{S}_{1}$ state at T-shape- $\mathrm{S}_{0}$ geometry in FIG. 7). ${ }^{32}$ Lastly, equal contributions from all four blocks characterizes a mixed state (for example, S1 at PD2-S in $_{0}$ FIG. 7). Omega matrices for the tetracene monomer and selected dimer geometries are included in the supporting information (Figs. S4-S8) for all methods used, along with CT value (Table SVIII), oscillator strength, and symmetry for each excited state (Tables SIII-SVII).

TABLE VII. Excitation energies (EE), irreducible representation of the $\mathrm{C}_{2}$ group (sym), and oscillator strengths $(f)$ for the Rot1-S Seometry $_{0}$ (FIG. 1). A lower-case letter beside each energy identifies analogous states among methods. Tables SIII-SVII present further data for all calculated geometries.

\begin{tabular}{|c|c|c|c|c|c|c|c|c|c|}
\hline \multirow[b]{2}{*}{ State } & \multicolumn{3}{|c|}{ DFT/MRCI } & \multicolumn{3}{|c|}{ SOS-ADC(2) } & \multicolumn{3}{|c|}{ LC-TD-DFTB2 } \\
\hline & $\begin{array}{c}\text { EE } \\
(\mathrm{eV})\end{array}$ & $f$ & sym & $\begin{array}{c}\text { EE } \\
(\mathrm{eV})\end{array}$ & $f$ & sym & $\begin{array}{c}\text { EE } \\
(\mathrm{eV})\end{array}$ & $f$ & sym \\
\hline $\mathrm{S}_{1}$ & $2.42 \mathrm{a}$ & 0.015 & A & $3.21 \mathrm{~b}$ & 0.003 & B & $2.89 \mathrm{~b}$ & 0.004 & B \\
\hline $\mathrm{S}_{2}$ & $2.57 \mathrm{~b}$ & 0.005 & B & $3.28 \mathrm{c}$ & 0.095 & A & $3.04 \mathrm{c}$ & 0.134 & A \\
\hline $\mathrm{S}_{3}$ & $2.68 \mathrm{c}$ & 0.159 & A & 3.48 & 0.014 & A & $3.12 \mathrm{a}$ & 0.020 & A \\
\hline $\mathrm{S}_{4}$ & $2.75 \mathrm{~d}$ & 0.098 & B & 3.48 & 0.010 & B & $3.14 \mathrm{~d}$ & 0.006 & B \\
\hline
\end{tabular}




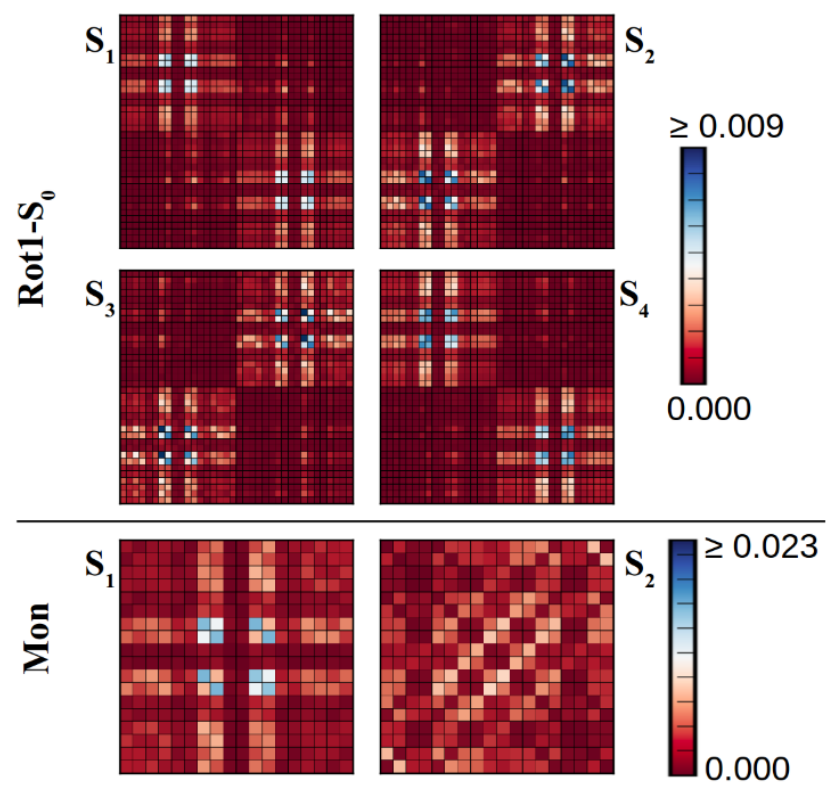

FIG. 6. $\mathrm{S}_{1}-\mathrm{S}_{4}$ DFT/MRCI omega matrices for tetracene dimer at Rot1-S $\mathrm{S}_{0}$ geometry. For comparison, $\mathrm{S}_{1}$ and $\mathrm{S}_{2}$ DFT/MRCI omega matrices for the monomer (Mon) are also shown. The complete set of omega matrices is shown in Figs. S4-S8.

Using these tools, we see that the order of analogous states varies with the method, as shown in TABLE VII for the Rot1-S 0 geometry (Tables SIII-SVII for all). However, for a given method, these inversions in the order of states are, in most cases, associated with states with relatively small energy differences $(<0.4 \mathrm{eV})$, suggesting a general agreement among methods. Concerning oscillator strengths, there is a good agreement among methods for all geometries regarding the identification of each state as bright $(f>0.05)$ or dark, as can be seen in FIG. 4 and FIG. 5 . Analyzing the $\mathrm{S}_{1}$ state for the T-shaped$\mathrm{S}_{0}$ structure, one can see from Tables SVI (lowercase letters besides excitation energies label comparable states) and SVIII, that the $\mathrm{S}_{1}$ state $\left({ }^{1} \mathrm{~B}_{1}\right)$ for DFT/MRCI and ADC(2) has a pronounced CT character and a smaller oscillator strength whereas the $2^{1} \mathrm{~B}_{1}$ state has a smaller CT character and a larger oscillator strength. For the other methods, this situation is inversed (for SOS-ADC(2) the $2^{1} \mathrm{~B}_{1} \mathrm{CT}$ value is 0.89 e, not included in Table SVIII). This inversion in the order of analogous states $\left(1^{1} \mathrm{~B}_{1}\right.$ and $\left.2{ }^{1} \mathrm{~B}_{1}\right)$ among 
different methods still seems acceptable, however, in view of the relatively small energy difference between these two states (0.22-0.35 eV for all methods).

Omega matrices (FIG. 6 to FIG. 8) provide further information, as they can be used to assign the state character as CT, CR, excitonic, localized, or mixed. ${ }^{32}$ At Rot1-S $\mathrm{S}_{0}$ geometry (FIG. 6), $\mathrm{S}_{1}$ to $\mathrm{S}_{4}$ states are connected to the $S_{1}$ state of the monomer, as shown by the patterns of the respective dimer omega matrices. The main patterns of the omega matrices for states $S_{2}$ and $S_{3}$ are located on the off-diagonal blocks showing an excitonic resonance character. On the other hand, $\mathrm{S}_{1}$ and $\mathrm{S}_{4}$ states are of charge resonance character as the diagonal blocks, connected to intermonomer interactions, are dominant in this case. CT values confirm this picture, as they are small for $S_{2}$ and $S_{3}(C T<0.15)$, and large for $S_{1}$ and $S_{4}$ (CT > 0.8). This situation is similar to the Frenkel models describing dimer states as combinations of monomer states, ${ }^{91}$ and the relevant role of charge-transfer interactions is consistent with a previous work that demonstrated that the inclusion of a charge-transfer type of coupling in the Holstein Hamiltonian is necessary to describe experimental results in a tetracene crystal. ${ }^{22}$
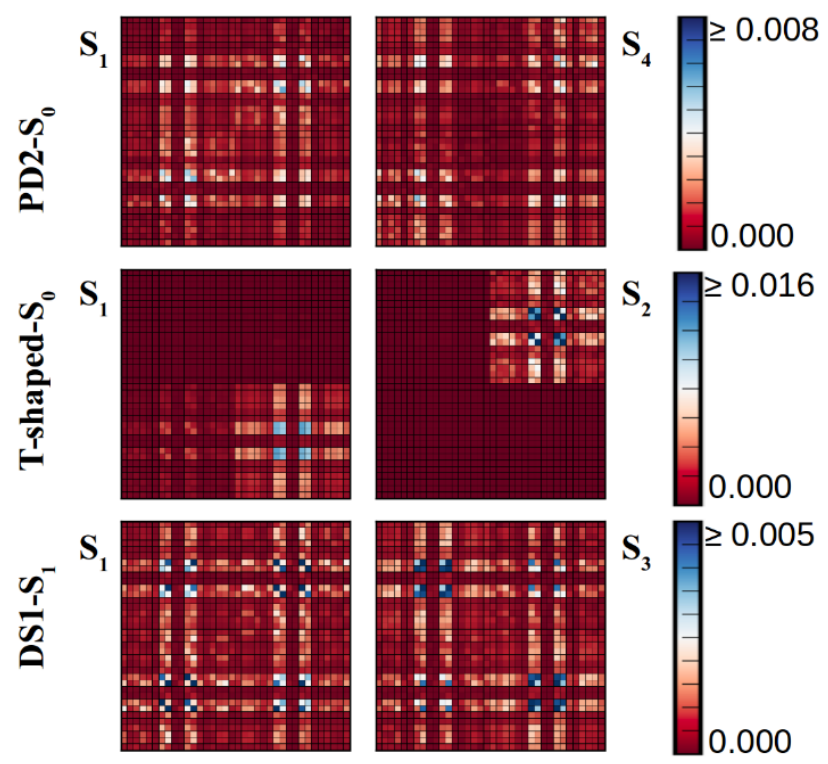

FIG. 7. DFT/MRCI omega matrices for tetracene dimer at geometries PD2-S 0 , T-shaped-S 0 , and DS1$\mathrm{S}_{1}$. The complete set of omega matrices is shown in Figs. S6-S8. 
DFT/MRCI predicts a more complex scenario for the other geometries. At the PD2-S $\mathrm{S}_{0}$ geometry, $\mathrm{S}_{1}$ and $\mathrm{S}_{4}$ are predicted to be mixed states (FIG. 7), and for the T-shaped- $\mathrm{S}_{0}$ (FIG. 7), $\mathrm{S}_{1}$ is a CT state, $\mathrm{S}_{2}$ and $\mathrm{S}_{3}$ (Fig. S8) are almost degenerate excitations localized at each monomer, and $\mathrm{S}_{4}$ is a doubly excited state. At DS1-S $S_{1}$ geometry, all $S_{1}-S_{4}$ DFT/MRCI states are predicted to be either of mixed ( $S_{1}$ and $S_{3}$, FIG. 7) or doubly excited character $\left(S_{2}\right.$ and $\left.S_{4}\right)$. For the $S_{1}$ state, the DFT/MRCI CT value is quite similar to other methods (Table SVIII), and shows that charge transfer interactions are relevant for the excimer. The splitting among singly excited states for the latter geometry is predicted to be much larger, close to $1 \mathrm{eV}$ (FIG. 9), suggesting a stronger interaction between monomers in this geometry. The considerable decrease in the $S_{1}$ state energy implies that this splitting is due to the excimer relaxation itself.

Despite the order inversions, LC-TD-DFTB2 predicts similar pictures regarding the nature of states (e.g., CR associated with monomer $\mathrm{S}_{1}$ ) and comparable $\mathrm{CT}$ values for the singly excited states, exceptions being states $\mathrm{S}_{2}$ and $\mathrm{S}_{3}$ at PD2-S $\mathrm{S}_{0}$ (FIG. 8), and $\mathrm{S}_{3}$ at DS1-S $\mathrm{S}_{1}$ geometry. In the latter cases, DFT/MRCI predicts states with more mixed character. In contrast to the other methods, SOS-ADC(2) predicts excitonic states connected to the $S_{2}$ state of the monomer (FIG. 6) among the low-lying states $-S_{3}$ and $\mathrm{S}_{4}$ at Rot1-S $\left(\right.$ FIG. 8), PD2-S $\mathrm{S}_{0}$ and T-shaped- $\mathrm{S}_{0}$ - instead of CT/CR, meaning that the latter types of state are destabilized relative to excitonic ones by this method. 


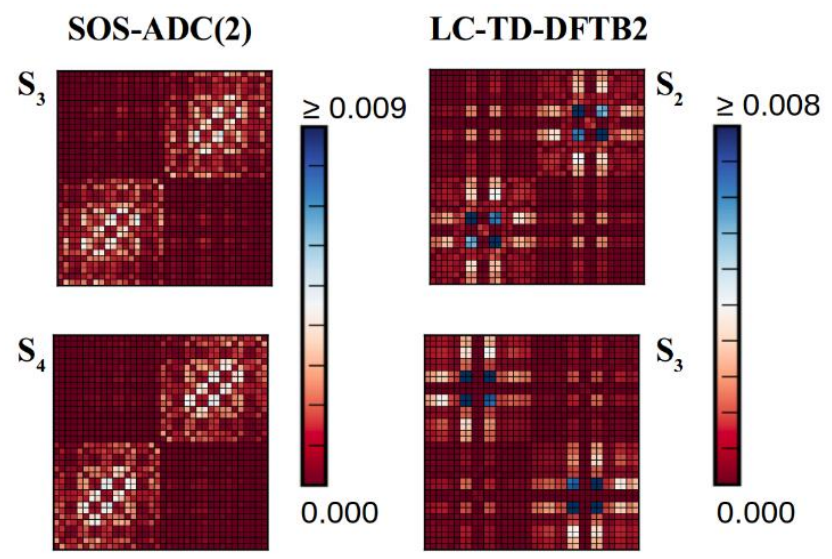

FIG. 8. Tetracene dimer omega matrices for SOS-ADC(2) at Rot1-S $\mathrm{S}_{0}$ geometry, and LC-TD-DFTB2 at

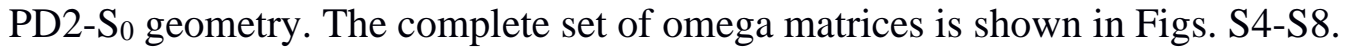

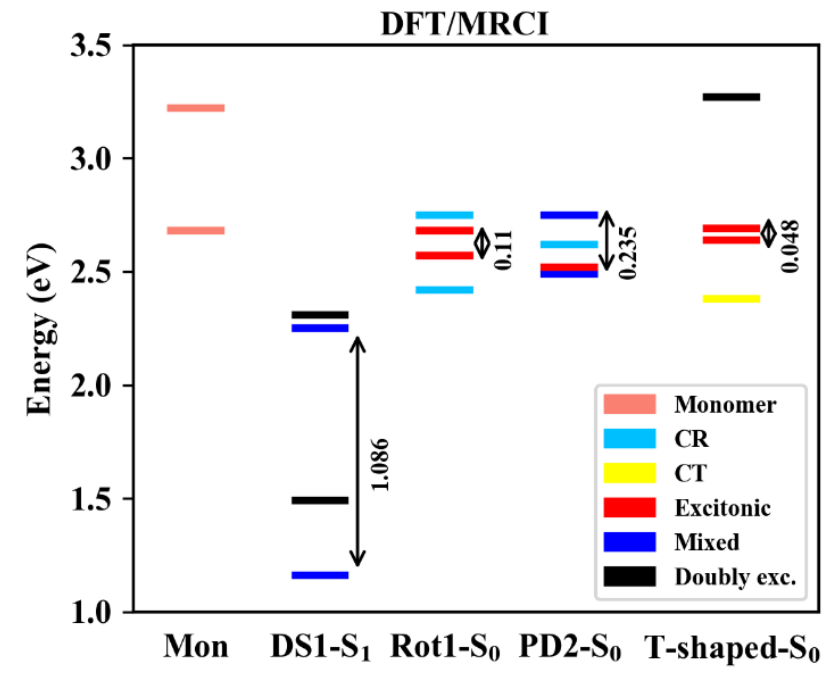

FIG. 9. DFT/MRCI vertical excitations for each tetracene dimer geometry and the monomer (Mon). $\mathrm{S}_{1}$ and $S_{2}$ states are represented for the monomer and $S_{1}$ to $S_{4}$ for the dimer. The nature of the state is represented by the line color. CR and CT stand for charge resonance and charge transfer, respectively. Mixed states have relevant contributions from both excitonic and charge-transfer interactions.

Energy level diagrams are shown in FIG. 9 for DFT/MRCI $\mathrm{S}_{1}-\mathrm{S}_{4}$ states with the splitting of states of similar character, summarizing the previous discussion based on FIG. 6 to FIG. 8. In the case of vertical 
excitations from $\mathrm{S}_{0}$, excitonic splittings amount to a few tenths of $\mathrm{eV}$. As mentioned earlier, the situation is quite different for the DS1-S 1 geometry, where the corresponding splitting increases to $1 \mathrm{eV}$, and the two singly-excited states are mixed excitonic and CT states.

\section{Potential Energy and Charge-Transfer Curves}

Potential energy curves (PECs) were used to analyze the relationship between charge transfer and excimer survival, and its differences among methods. SOS-ADC(2), TD- $\omega$ B97X-D, LC-TD-DFTB2, and DFT/MRCI were used. The lowest energy $\mathrm{S}_{1}$ minimum geometry (DS1-S 1 , FIG. 3) was taken as the starting point. For DFT/MRCI and LC-TD-DFTB2, the SOS-ADC(2) optimized geometry was used. To construct the PEC, one monomer was rigidly displaced along the normal vector of the plane defined by the three yellow atoms in FIG. 2, whereas the other monomer was kept fixed. Symmetry labels were used to identify states, except for LC-TD-DFTB2, since orbitals for the latter method became localized to each monomer, for large intermonomer distances. 

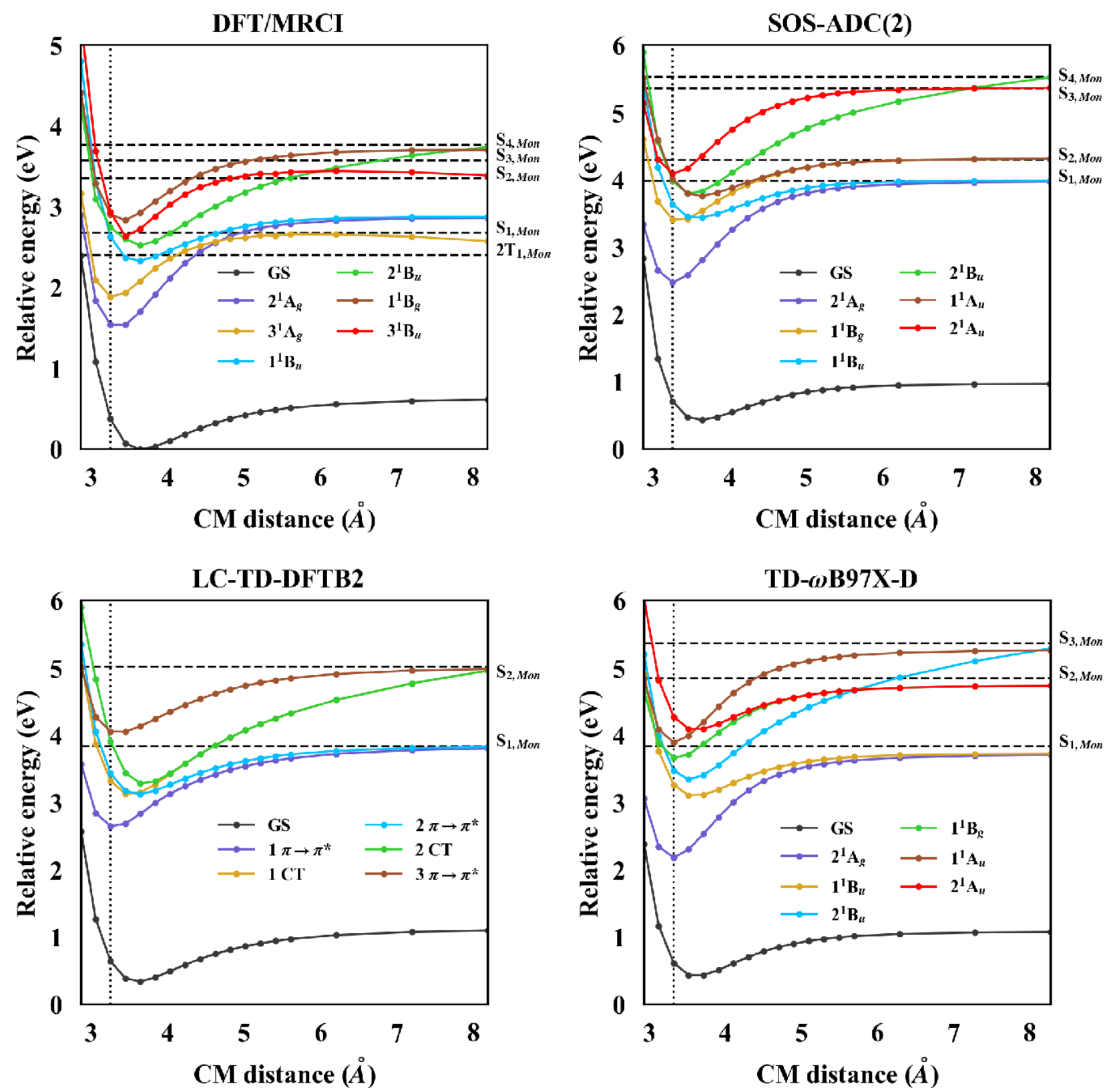

FIG. 10: Diabatically connected PEC along the intermonomer distance for the tetracene dimer. Energies are relative to the Rot1- $\mathrm{S}_{0}$ minimum, except for DFT/MRCI, for which the lowest value of the $\mathrm{S}_{0}$ energy $(3.65 \AA)$ was used as a reference. The DS1-S 1 optimized geometry is marked with a dotted vertical line. The excited states of the monomer (Mon) are represented as horizontal lines. In LC-TD-DFTB2 case, states were labeled based on their character, as symmetry labels were not applicable. 
TABLE VIII. Dissociation energy $\left(\mathrm{D}_{\mathrm{e}}, \mathrm{eV}\right)$ for each state. The DFT/MRCI $\mathrm{S}_{1}$ to $\mathrm{S}_{4}$ states at the DS1-S geometry were included. CT and doubly excited (DE) states were not included. The lower-case letter besides each value is used to mark analogous states.

\begin{tabular}{ccccc}
\hline \multirow{2}{*}{ Method } & \multicolumn{4}{c}{ State } \\
\cline { 2 - 5 } & $\mathbf{S}_{\mathbf{1}}{ }^{*}$ & $\mathbf{S}_{\mathbf{2}}{ }^{*}$ & $\mathbf{S}_{\mathbf{3}}{ }^{*}$ & $\mathbf{S}_{\mathbf{4}}{ }^{*}$ \\
\hline DFT/MRCI & $1.32 \mathrm{a}$ & $\mathrm{DE}$ & $0.54 \mathrm{c}$ & $\mathrm{DE} / \mathrm{CT}$ \\
SOS-ADC(2) & $1.49 \mathrm{a}$ & $0.90 \mathrm{~b}$ & $0.55 \mathrm{c}$ & $\mathrm{CT} \mathrm{d}$ \\
TD- $\omega$ B97X-D & $1.52 \mathrm{a}$ & $0.62 \mathrm{c}$ & $\mathrm{CT} \mathrm{d}$ & $1.07 \mathrm{~b}$ \\
LC-TD-DFTB2 & $1.16 \mathrm{a}$ & $\mathrm{CT} \mathrm{d}$ & $0.7 \mathrm{c}$ & $\mathrm{CT} \mathrm{b}$ \\
\hline * the state number refers to DFT/MRCI at DS1-S 1 geometry.
\end{tabular}

As can be seen from FIG. 10, all single-reference methods predict a similar general profile relative to DFT/MRCI, but relevant differences are found, such as a shallower $S_{1}$ state minimum $\left(2^{1} A_{g}\right.$ for all methods) and smaller energy gaps between states $\mathrm{S}_{2}-\mathrm{S}_{4}$ in LC-TD-DFTB2. Among the singly excited states, the description of the most analogous states is quite similar, as shown by the dissociation energies in TABLE VIII. Excimer stabilization energies for the $S_{1}$ state also agree quite well among singlereference methods (TABLE IX). The most important difference of single-reference methods relative to DFT/MRCI is the low-lying doubly excited state $\left(3^{1} \mathrm{~A}_{\mathrm{g}}\right)$ in the latter, which crosses with the state associated with the excimer $\left(2^{1} \mathrm{~A}_{\mathrm{g}}\right)$, and could lead to significant deficiencies in the description of photophysical processes by single-reference methods. This crossing is similar to previously reported results for a pentacene dimer. ${ }^{90}$ Similarly, a previous study of an intermonomer displacement curve at double spin-flip restricted active space level for two stacked $\mathrm{D}_{2 \mathrm{~h}}$ tetracene monomers ${ }^{8}$ also reported a low-lying doubly excited ${ }^{1} \mathrm{~A}_{\mathrm{g}}$ state, which becomes nearly degenerate with $\mathrm{S}_{1}$. As shown in FIG. 10, the doubly excited $3^{1} \mathrm{~A}_{\mathrm{g}}$ state has energy near twice the $\mathrm{T}_{1}$ state energy of the monomer, suggesting it is the state involved in the singlet fission process. 
TABLE IX. $\mathrm{S}_{1}$ excimer stabilization energy (ESE), predicted as the difference between the vertical excitation energy (VE) and adiabatic excitation energy (AE). All values are in eV.

\begin{tabular}{|c|c|c|c|c|}
\hline Energy & SOS-ADC(2) & 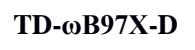 & TD-CAM-B3LYP & LC-TD-DFTB2 \\
\hline VE & 3.21 & 2.88 & 3.06 & 2.89 \\
\hline $\mathrm{AE}$ & 2.47 & 2.19 & 2.30 & 2.37 \\
\hline ESE & 0.74 & 0.69 & 0.76 & 0.52 \\
\hline
\end{tabular}



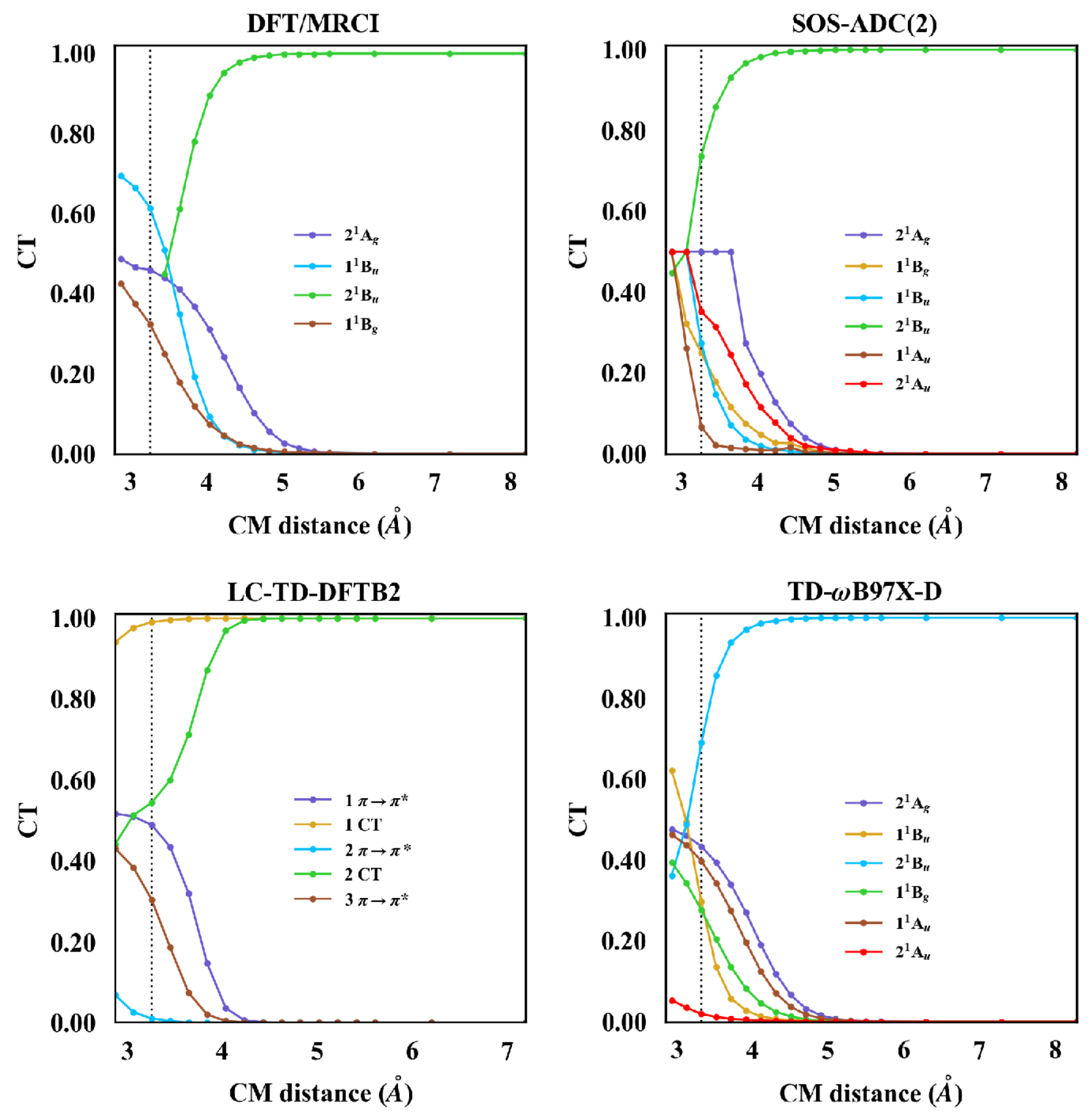

FIG. 11: Diabatically connected CT curves along the intermonomer distance for the tetracene dimer. DS1-S $1_{1}$ optimized geometry is marked with a dotted vertical line. $3^{1} \mathrm{Ag}_{\mathrm{g}}$ and part of the $2{ }^{1} \mathrm{~B}_{\mathrm{u}} \mathrm{DFT} / \mathrm{MRCI}$ states weres excluded due to the dominant doubly excited character. 
Diabatically connected CT values for the PECs in FIG. 10 are given in FIG. 11
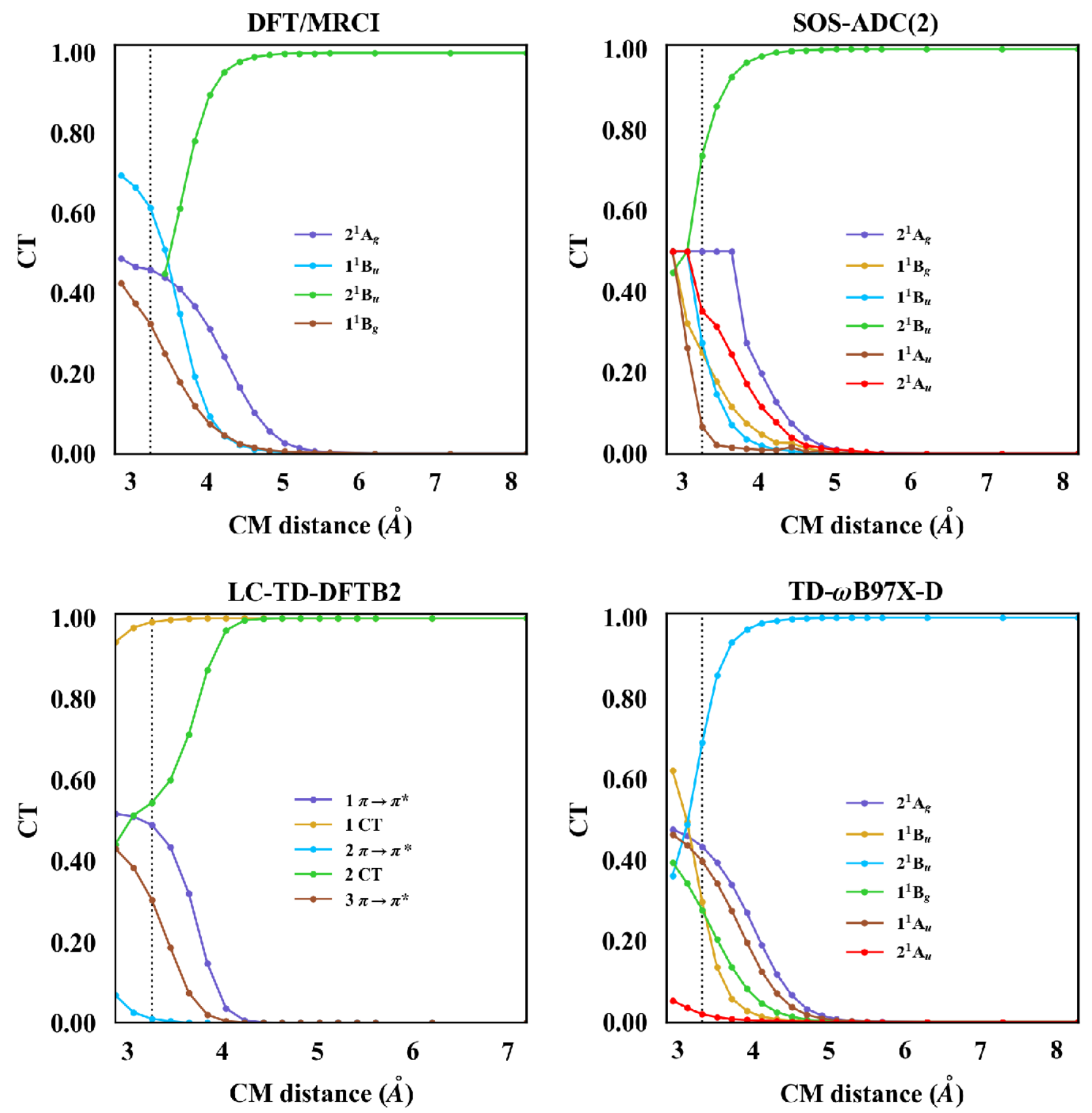

FIG. 11. When analyzed together, PECs and CT values reveal that the decrease of potential energy associated with excimer survival in $\mathrm{S}_{1}$ mirrors the increase of intermonomer charge transfer, measured by CT values. Excluding CT and doubly excited states, this is also valid for higher-lying states. Focusing on DFT/MRCI, a comparison of the $2{ }^{1} \mathrm{~A}_{\mathrm{g}}$ and $1{ }^{1} \mathrm{~B}_{\mathrm{u}} \mathrm{PEC}$ and CT curves suggests that the dissociation energy $\left(D_{e}\right)$ is proportional to the distance upon which charge-transfer interactions vanish $\left(D_{C T}\right.$, the point 
at which CT becomes very small, e.g., 0.05). This correlation is not always monotonous, however, as exemplified by the $1^{1} \mathrm{~B}_{\mathrm{g}}$ state in the DFT/MRCI curve in FIG. 12. Hence, charge-transfer interactions could have a prominant role in the first two states, but not in the latter. Due to the absence of doubly excited states, SOS-ADC(2) presents a clearer picture and corroborates the previous relation, as both $\mathrm{D}_{\mathrm{e}}$ and $\mathrm{D}_{\mathrm{CT}}$ decrease in the order $2^{1} \mathrm{~A}_{\mathrm{g}}, 2^{1} \mathrm{~A}_{\mathrm{u}}, 1^{1} \mathrm{~B}_{\mathrm{g}}$, and $1{ }^{1} \mathrm{~B}_{\mathrm{u}}$, whereas $1{ }^{1} \mathrm{~A}_{\mathrm{u}}$ does not properly fit this tendency (FIG. 12). TD- $\omega B$ B7X-D method presents similar results, although exchanging the roles of $1^{1} \mathrm{~A}_{\mathrm{u}}$ and $2{ }^{1} \mathrm{~A}_{u}$. Lastly, the first three $\pi \rightarrow \pi^{*}$ LC-TD-DFTB2 states also fit this tendency, specifically in the following order: $1 \pi \rightarrow \pi^{*}, 3 \pi \rightarrow \pi^{*}$, and $2 \pi \rightarrow \pi^{*}$. A similar qualitative relation also appears in previously reported results for the benzene dimer PEC and CT curves, ${ }^{38}$ as states with negligible CT values remain unbounded, and states with deeper wells are associated with CT values that vanish at larger intermonomer distances.

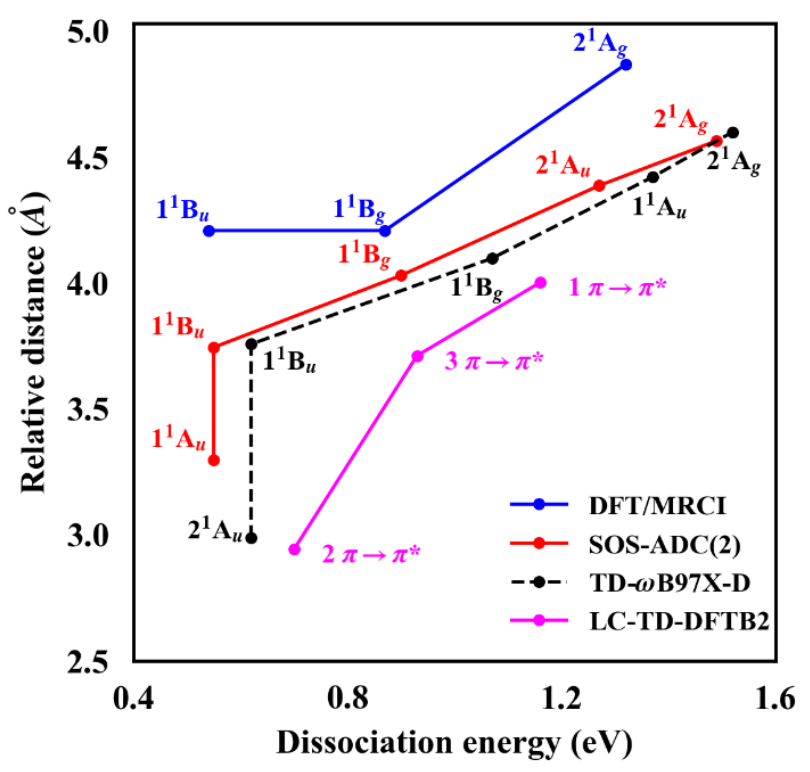


FIG. 12: Correlation between relative distance at which the CT curve becomes smaller than 0.05 (FIG.
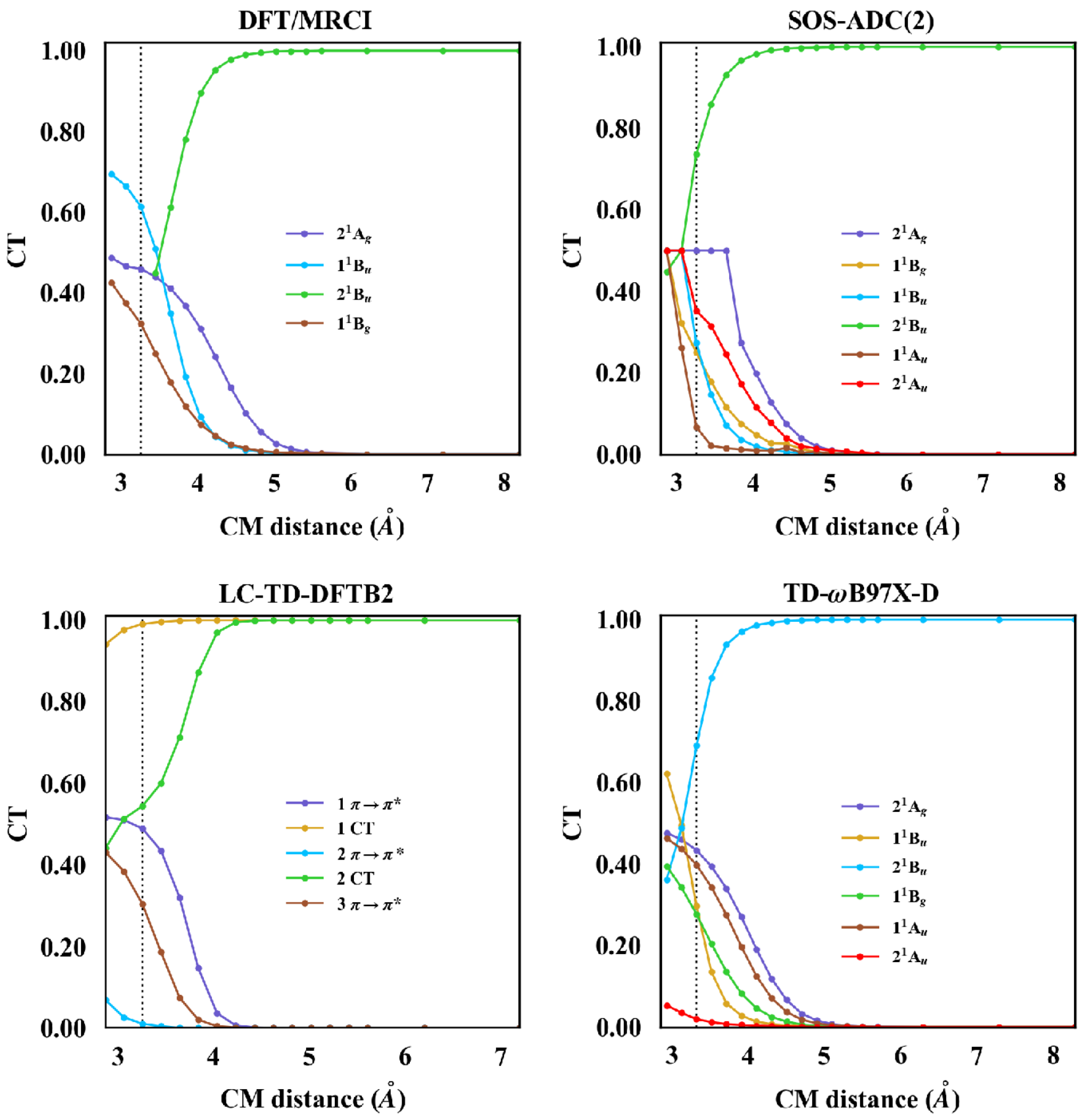

FIG. 11) compared to dissociation energy (FIG. 10) for each state. 


\section{CONCLUSIONS}

Benchmark results were reported for the tetracene dimer using single-reference methods and DFT/MRCI. Results of the latter method are consistent with available experimental data for absorption spectra. We predict emission excitation energies for the excimer that are significantly lower than existing experimental data for tetracene dimers that do not present typical excimer behavior. Our calculations suggest that these excitation energies might be useful to differentiate excimer formation from other structural changes between tetracene dimers upon absorption.

Among the tested methods, consistent results were predicted for optimized geometries of $S_{0}$ and $S_{1}$ states and for the corresponding excitation spectra. Comparison of omega matrices shows that the specific nature of states varies appreciably with dimer geometry. Particularly at the excimer geometry (DS1-S 1 , the geometry relaxation leads to a more complex scenario, with low-lying mixed character as well as doubly excited states. The first low-lying doubly excited state has an asymptotic energy value in the potential energy curve consistent with that of two times the energy of the monomer $\mathrm{T}_{1}$ state, confirming that it is the state connected to singlet fission. This state is also found to cross the state associated with the excimer and becoming the lowest state asymptotically for large intermonomer distances, and, therefore, should be relevant in the singlet fission process. The absence of the doubly excited state can also lead to problems in the description of general excimer related processes by single-reference methods.

LC-TD-DFTB2 provides a good overall description of optimized geometries, associated spectrum, and the nature of low-lying singly excited states, relative to other single-reference methods. Inversions in the order of low-lying states relative to DFT/MRCI and other methods occurred mostly among energetically close states (gaps lower than $0.4 \mathrm{eV}$ ). Relative energies of ground-state conformers suggest a flatter potential energy curve relative to SOS-MP2, but excited-state conformers agree quite well with 
the prediction of other methods. Hence, LC-TD-DFTB2 should be able to provide a description of the excimer formation and survival processes in line with other single-reference methods.

Results based on PEC and CT curves suggest that charge-transfer interactions are necessary for the excimer stabilization. This could be expressed qualitatively as a relation between the dissociation energy of each state and the associated CT curve vanishing distance. Hence, charge-transfer interactions are an important contribution to the excimer state and to several of the higher states.

\section{SUPPLEMENTARY MATERIAL}

The data that supports the findings of this study are available within the article and its supplementary material. See the supplementary material for vertical excitations energies, oscillator strengths, omega matrices (with fragmentation scheme), orbital analysis, and $S_{0}$ and $S_{1}$ optimized geometries cartesian coordinates for tetracene monomer and dimer. For the latter, intermonomer CT values and DFT/MRCI reference active space tests are also included.

\section{ACKNOWLEDGMENTS}

This study was financed in part by the Coordenação de Aperfeiçoamento de Pessoal de Nível Superior - Brasil (CAPES) - Finance Code 001. The authors acknowledge the computer time provided by the School of Pharmaceutical Science and Technology (SPST) at Tianjin University, Tianjin, China, on the computer cluster Arran. The authors acknowledge the High Performance Computing Center (HPCC) at Texas Tech University for providing computational resources that have contributed to the research results reported within this paper. URL: http://www.hpcc.ttu.edu. MTC acknowledges the Conselho Nacional de Desenvolvimento Científico e Tecnológico $(\mathrm{CNPq})$ and the Fundação de Apoio à Pesquisa do Estado 
do Rio de Janeiro (FAPERJ), within the Bolsa Nota 10 program for financial support. MTC and MB thank the support of the FetOpen grant BoostCrop (Grant agreement 828753) and the project Equip@Meso (ANR-10-EQPX-29-01). TAN likes to thank the Laboratoire d'Excellence iMUST. This work was supported by the Center for Integrated Nanotechnologies (Project No. 2019BC0064), an Office of Science User Facility operated for the U.S. Department of Energy Office of Science by Los Alamos National Laboratory (Contract No. 89233218CNA000001) and Sandia National Laboratories (Contract No. DE-NA-0003525).

\section{DATA AVAILABILITY}

The data that supports the findings of this study are available within the article and its supplementary material.

\section{REFERENCES}

${ }^{1}$ O. Ostroverkhova, Chem. Rev. 116, 13279 (2016).

2 J.E. Anthony, Angew. Chemie Int. Ed. 47, 452 (2008).

${ }^{3}$ Y.-W. Son, M.L. Cohen, and S.G. Louie, Nature 444, 347 (2006).

${ }^{4}$ A. Candian and C.J. Mackie, Int. J. Quantum Chem. 117, 146 (2017).

${ }^{5}$ M. Nakano and B. Champagne, J. Phys. Chem. Lett. 6, 3236 (2015).

${ }^{6}$ D. Casanova, Chem. Rev. 118, 7164 (2018).

${ }^{7}$ P.M. Zimmerman, F. Bell, D. Casanova, and M. Head-Gordon, J. Am. Chem. Soc. 133, 19944 (2011).

${ }^{8}$ X. Feng, A. V. Luzanov, and A.I. Krylov, J. Phys. Chem. Lett. 4, 3845 (2013).

${ }^{9}$ L.E. Aguilar Suarez, M.F.S.J. Menger, and S. Faraji, Mol. Phys. 8976, 1 (2020). 
10 J. Han, D.R. Rehn, T. Buckup, and A. Dreuw, J. Phys. Chem. A (2020) DOI:

10.1021/acs.jpca.0c07236.

${ }^{11}$ C.B. Dover, J.K. Gallaher, L. Frazer, P.C. Tapping, A.J. Petty, M.J. Crossley, J.E. Anthony, T.W.

Kee, and T.W. Schmidt, Nat. Chem. 10, 305 (2018).

12 M.T. Trinh, A. Pinkard, A.B. Pun, S.N. Sanders, E. Kumarasamy, M.Y. Sfeir, L.M. Campos, X. Roy, and X.-Y. Zhu, Sci. Adv. 3, e1700241 (2017).

13 T. Minami and M. Nakano, J. Phys. Chem. Lett. 3, 145 (2012).

${ }^{14}$ F. Plasser, H. Pašalić, M.H. Gerzabek, F. Libisch, R. Reiter, J. Burgdörfer, T. Müller, R. Shepard, and H. Lischka, Angew. Chemie Int. Ed. 52, 2581 (2013).

${ }^{15}$ E. Posenitskiy, M. Rapacioli, B. Lepetit, Di. Lemoine, and F. Spiegelman, Phys. Chem. Chem. Phys. 21, 12139 (2019).

${ }^{16}$ F. Spillebout, D. Bégué, I. Baraille, and J.M. Shaw, Energy \& Fuels 28, 2933 (2014).

${ }^{17}$ M. Krämer, P.M. Dohmen, W. Xie, D. Holub, A.S. Christensen, and M. Elstner, J. Chem. Theory Comput. 16, 4061 (2020).

${ }^{18}$ A. Kubas, F. Hoffmann, A. Heck, H. Oberhofer, M. Elstner, and J. Blumberger, J. Chem. Phys. 140, 104105 (2014).

${ }^{19}$ P.B. Lutz and C.A. Bayse, Phys. Chem. Chem. Phys. 15, 9397 (2013).

${ }^{20}$ E. Titov, A. Humeniuk, and R. Mitrić, Phys. Chem. Chem. Phys. 20, 25995 (2018).

${ }^{21}$ B. Shi, D. Nachtigallová, A.J.A. Aquino, F.B.C. Machado, and H. Lischka, Phys. Chem. Chem. Phys. 21, 9077 (2019).

${ }^{22}$ H. Yamagata, J. Norton, E. Hontz, Y. Olivier, D. Beljonne, J.L. Brédas, R.J. Silbey, and F.C. Spano, J. Chem. Phys. 134, 204703 (2011).

${ }^{23}$ X. Feng and A.I. Krylov, Phys. Chem. Chem. Phys. 18, 7751 (2016).

24 J.A. Katul and A.B. Zahlan, J. Chem. Phys. 47, 1012 (1967). 
${ }^{25}$ M.A. Iannone and G.W. Scott, Chem. Phys. Lett. 171, 569 (1990).

${ }^{26}$ C. Schouder, A.S. Chatterley, F. Calvo, L. Christiansen, and H. Stapelfeldt, Struct. Dyn. 6, 044301 (2019).

27 N.J. Silva, F.B.C. Machado, H. Lischka, and A.J.A. Aquino, Phys. Chem. Chem. Phys. 18, 22300 (2016).

${ }^{28}$ P.M. Zimmerman, C.B. Musgrave, and M. Head-Gordon, Acc. Chem. Res. 46, 1339 (2013).

${ }^{29}$ N. Elfers, I. Lyskov, J.D. Spiegel, and C.M. Marian, J. Phys. Chem. C 120, 13901 (2016).

${ }^{30}$ G. Tao, J. Chem. Phys. 151, 054308 (2019).

${ }^{31}$ S. Ito, T. Nagami, and M. Nakano, J. Photochem. Photobiol. C Photochem. Rev. 34, 85 (2018).

${ }^{32}$ F. Plasser and H. Lischka, J. Chem. Theory Comput. 8, 2777 (2012).

${ }^{33}$ F. Plasser, M. Wormit, and A. Dreuw, J. Chem. Phys. 141, 024106 (2014).

${ }^{34}$ F. Plasser, "TheoDORE: A package for theoretical density, orbital relaxation, and exciton analysis", available from http://theodore-qc.sourceforge.net.

35 J.B. Birks, Reports Prog. Phys. 38, 903 (1975).

${ }^{36}$ Q. Ge and M. Head-Gordon, J. Chem. Theory Comput. 14, 5156 (2018).

37 T. Azumi, A.T. Armstrong, and S.P. McGlynn, J. Chem. Phys. 41, 3839 (1964).

38 T.M. Cardozo, A.P. Galliez, I. Borges, F. Plasser, A.J.A. Aquino, M. Barbatti, and H. Lischka, Phys. Chem. Chem. Phys. 21, 13916 (2019).

${ }^{39}$ M. Elstner, D. Porezag, G. Jungnickel, J. Elsner, M. Haugk, T. Frauenheim, S. Suhai, and G. Seifert, Phys. Rev. B 58, 7260 (1998).

${ }^{40}$ A. Humeniuk and R. Mitrić, J. Chem. Phys. 143, 134120 (2015).

${ }^{41}$ J.J. Kranz, M. Elstner, B. Aradi, T. Frauenheim, V. Lutsker, A.D. Garcia, and T.A. Niehaus, J. Chem. Theory Comput. 13, 1737 (2017).

42 J. Hoche, H.-C. Schmitt, A. Humeniuk, I. Fischer, R. Mitrić, and M.I.S. Röhr, Phys. Chem. Chem. 
Phys. 19, 25002 (2017).

${ }^{43}$ Y. Jung, R.C. Lochan, A.D. Dutoi, and M. Head-Gordon, J. Chem. Phys. 121, 9793 (2004).

44 J.-D. Chai and M. Head-Gordon, Phys. Chem. Chem. Phys. 10, 6615 (2008).

45 A. Hellweg, S.A. Grün, and C. Hättig, Phys. Chem. Chem. Phys. 10, 4119 (2008).

${ }^{46}$ M. Gaus, Q. Cui, and M. Elstner, J. Chem. Theory Comput. 7, 931 (2011).

47 T. Yanai, D.P. Tew, and N.C. Handy, Chem. Phys. Lett. 393, 51 (2004).

${ }^{48}$ A. Dreuw and M. Wormit, Wiley Interdiscip. Rev. Comput. Mol. Sci. 5, 82 (2015).

49 J. Schirmer, Phys. Rev. A 26, 2395 (1982).

50 S. Grimme and M. Waletzke, J. Chem. Phys. 111, 5645 (1999).

${ }^{51}$ C.M. Marian, A. Heil, and M. Kleinschmidt, WIREs Comput. Mol. Sci. 9, e1394 (2019).

52 B. Shi, D. Nachtigallová, A.J.A. Aquino, F.B.C. Machado, and H. Lischka, J. Chem. Phys. 150, 124302 (2019).

53 B. Shi, D. Nachtigallová, A.J.A. Aquino, F.B.C. Machado, and H. Lischka, J. Phys. Chem. Lett. 10, 5592 (2019).

54 S.A. Bäppler, F. Plasser, M. Wormit, and A. Dreuw, Phys. Rev. A - At. Mol. Opt. Phys. 90, 45 (2014).

${ }^{55}$ F. Furche, R. Ahlrichs, C. Hättig, W. Klopper, M. Sierka, and F. Weigend, Wiley Interdiscip. Rev. Comput. Mol. Sci. 4, 91 (2014).

${ }^{56}$ TURBOMOLE V7.2 2017, a development of University of Karlsruhe and Forschungszentrum Karlsruhe GmbH, 1989-2007,TURBOMOLE GmbH, since 2007; available from http://www.turbomole.com.

${ }^{57}$ C. Hättig and F. Weigend, J. Chem. Phys. 113, 5154 (2000).

${ }^{58}$ C. Hättig, J. Chem. Phys. 118, 7751 (2003).

${ }^{59}$ A. Köhn and C. Hättig, J. Chem. Phys. 119, 5021 (2003). 
${ }^{60}$ F. Weigend, M. Häser, H. Patzelt, and R. Ahlrichs, Chem. Phys. Lett. 294, 143 (1998).

${ }^{61}$ F. Neese, WIREs Comput. Mol. Sci. 2, 73 (2012).

${ }^{62}$ F. Neese, WIREs Comput. Mol. Sci. 8, 4 (2018).

${ }^{63}$ M. J. Frisch, G. W. Trucks, H. B. Schlegel, G. E. Scuseria, M. A. Robb, J. R. Cheeseman, G.

Scalmani, V. Barone, B. Mennucci, G. A. Petersson, H. Nakatsuji, M. Caricato, X. Li, H. P. Hratchian, A. F. Izmaylov, J. Bloino, G. Zheng, J. L. Sonnenberg, M. Hada, M. Ehara, K. Toyota, R. Fukuda, J. Hasegawa, M. Ishida, T. Nakajima, Y. Honda, O. Kitao, H. Nakai, T. Vreven, J. A. Montgomery, Jr., J. E. Peralta, F. Ogliaro, M. Bearpark, J. J. Heyd, E. Brothers, K. N. Kudin, V. N. Staroverov, T. Keith, R. Kobayashi, J. Normand, K. Raghavachari, A. Rendell, J. C. Burant, S. S. Iyengar, J. Tomasi, M. Cossi, N. Rega, J. M. Millam, M. Klene, J. E. Knox, J. B. Cross, V. Bakken, C. Adamo, J. Jaramillo, R. Gomperts, R. E. Stratmann, O. Yazyev, A. J. Austin, R. Cammi, C. Pomelli, J. W. Ochterski, R. L. Martin, K. Morokuma, V. G. Zakrzewski, G. A. Voth, P. Salvador, J. J. Dannenberg, S. Dapprich, A. D. Daniels, O. Farkas, J. B. Foresman, J. V. Ortiz, J. Cioslowski, and D. J. Fox, Gaussian 09, Revision E.01, Gaussian, Inc., Wallingford CT, 2013.

${ }^{64}$ F. Weigend, Phys. Chem. Chem. Phys. 8, 1057 (2006).

${ }^{65}$ A. Hellweg, C. Hättig, S. Höfener, and W. Klopper, Theor. Chem. Acc. 117, 587 (2007).

${ }^{66}$ S. Grimme, S. Ehrlich, and L. Goerigk, J. Comput. Chem. 32, 1456 (2011).

67 S. Grimme, J. Antony, S. Ehrlich, and H. Krieg, J. Chem. Phys. 132, 154104 (2010).

${ }^{68}$ I. Lyskov, M. Kleinschmidt, and C.M. Marian, J. Chem. Phys. 144, 034104 (2016).

${ }^{69}$ A. Heil, M. Kleinschmidt, and C.M. Marian, J. Chem. Phys. 149, 164106 (2018).

${ }^{70}$ M. Kleinschmidt, C.M. Marian, M. Waletzke, and S. Grimme, J. Chem. Phys. 130, 044708 (2009).

${ }^{71}$ A.D. Becke, J. Chem. Phys. 98, 1372 (1993).

${ }^{72}$ R. Crespo-Otero and M. Barbatti, J. Chem. Phys. 134, 164305 (2011).

${ }^{73}$ F. Weigend and R. Ahlrichs, Phys. Chem. Chem. Phys. 7, 3297 (2005). 
${ }^{74}$ B. Hourahine, B. Aradi, V. Blum, F. Bonafé, A. Buccheri, C. Camacho, C. Cevallos, M.Y. Deshaye, T. Dumitrică, A. Dominguez, S. Ehlert, M. Elstner, T. van der Heide, J. Hermann, S. Irle, J.J. Kranz, C. Köhler, T. Kowalczyk, T. Kubař, I.S. Lee, V. Lutsker, R.J. Maurer, S.K. Min, I. Mitchell, C. Negre, T.A. Niehaus, A.M.N. Niklasson, A.J. Page, A. Pecchia, G. Penazzi, M.P. Persson, J. Řezáč, C.G. Sánchez, M. Sternberg, M. Stöhr, F. Stuckenberg, A. Tkatchenko, V.W.Z. Yu, and T. Frauenheim, J. Chem. Phys. 152, 124101 (2020).

${ }^{75}$ V.Q. Vuong, J. Akkarapattiakal Kuriappan, M. Kubillus, J.J. Kranz, T. Mast, T.A. Niehaus, S. Irle, and M. Elstner, J. Chem. Theory Comput. 14, 115 (2018).

${ }^{76}$ M. Gaus, A. Goez, and M. Elstner, J. Chem. Theory Comput. 9, 338 (2013).

${ }^{77}$ L. Zhechkov, T. Heine, S. Patchkovskii, G. Seifert, and H.A. Duarte, J. Chem. Theory Comput. 1, 841 (2005).

${ }^{78}$ A.K. Rappe, C.J. Casewit, K.S. Colwell, W.A. Goddard, and W.M. Skiff, J. Am. Chem. Soc. 114, 10024 (1992).

${ }^{79} \mathrm{Jmol}$ : an open-source Java viewer for chemical structures in 3D. http://www.jmol.org/.

${ }^{80}$ R. Nieman, A.J.A. Aquino, and H. Lischka, J. Chem. Phys. 152, 044306 (2020).

${ }^{81}$ H. Takeuchi, Comput. Theor. Chem. 1021, 84 (2013).

${ }^{82}$ C. Gonzalez and E.C. Lim, J. Phys. Chem. A 104, 2953 (2000).

83 S.M. Ryno, C. Risko, and J.-L. Brédas, Chem. Mater. 28, 3990 (2016).

${ }^{84}$ S. Tsuzuki, K. Honda, T. Uchimaru, and M. Mikami, J. Chem. Phys. 120, 647 (2004).

${ }^{85}$ C.M. Marian and N. Gilka, J. Chem. Theory Comput. 4, 1501 (2008).

${ }^{86}$ F. Bettanin, L.F.A. Ferrão, M. Pinheiro, A.J.A. Aquino, H. Lischka, F.B.C. Machado, and D. Nachtigallova, J. Chem. Theory Comput. 13, 4297 (2017).

${ }^{87}$ D. Biermann and W. Schmidt, J. Am. Chem. Soc. 102, 3163 (1980).

${ }^{88}$ N. Nijegorodov, V. Ramachandran, and D.P. Winkoun, Spectrochim. Acta Part A Mol. Biomol. 
Spectrosc. 53, 1813 (1997).

${ }^{89}$ P. Elliott, S. Goldson, C. Canahui, and N.T. Maitra, Chem. Phys. 391, 110 (2011).

${ }^{90}$ P.M. Zimmerman, Z. Zhang, and C.B. Musgrave, Nat. Chem. 2, 648 (2010).

91 G.D. Scholes and G. Rumbles, Nat. Mater. 5, 683 (2006). 